\title{
Loan and Inheritance Patterns in Hunter-Gatherer Ethnobiological Systems
}

Author(s): Claire Bowern, Hannah Haynie, Catherine Sheard, Barry Alpher,

Patience Epps, Jane Hill, and Patrick McConvell

Source: Journal of Ethnobiology, 34(2):195-227. 2014.

Published By: Society of Ethnobiology

DOI: http://dx.doi.org/10.2993/0278-0771-34.2.195

URL: http://www.bioone.org/doi/full/10.2993/0278-0771-34.2.195

BioOne (www.bioone.org) is a nonprofit, online aggregation of core research in the biological, ecological, and environmental sciences. BioOne provides a sustainable online platform for over 170 journals and books published by nonprofit societies, associations, museums, institutions, and presses.

Your use of this PDF, the BioOne Web site, and all posted and associated content indicates your acceptance of BioOne's Terms of Use, available at www.bioone.org/page/ terms of use.

Usage of BioOne content is strictly limited to personal, educational, and non-commercial use. Commercial inquiries or rights and permissions requests should be directed to the individual publisher as copyright holder. 


\title{
LOAN AND INHERITANCE PATTERNS IN HUNTER-GATHERER ETHNOBIOLOGICAL SYSTEMS
}

\author{
Claire Bowern ${ }^{1}$, Hannah Haynie ${ }^{2}$, Catherine Sheard ${ }^{3}$, Barry Alpher ${ }^{4}$, \\ Patience Epps ${ }^{5}$, Jane Hill' ${ }^{6}$, and Patrick McConvell ${ }^{7}$
}

We compare the etymologies of ethnobiological nomenclature in 130 hunter-gatherer and agriculturist languages in Australia, North America, and Amazonia. Previous work has identified correlations between systems of ethnobiological terminology and dominant means of community subsistence, relating stability of terminology to the "salience" of the items. However, the relevance of subsistence patterns to the development of ethnobiological nomenclature requires further investigation, as does the notion of "salience" and how it might relate to etymological stability. The current study probes the relationship between salience and stability and the variability within this relationship. We refine the notion of stability by studying both inheritance and loan rates. We refine the notion of "salience" by separately testing retention and loan rates in flora and fauna vocabulary that might be considered salient for different reasons. Results indicate that the most etymologically stable items are core foodstuffs (whether cultivated or wild). Psychotropic items were more likely to be loaned. There were no significant patterns for cultivar status or trade, though we note that the most frequently loaned items in the sample are also traded.

Keywords: historical linguistics, ethnobiological nomenclature, subsistence patterns, hunter-gatherers

Comparamos las etimologías de nombres etnobiológicas en 130 idiomas de grupos recolectores-cazadores y cultivadores de Australia, Norteamérica, y Amazonia. En investigaciones previas, se ha identificado correlaciones entre los sistemas de terminología etnobiológica y los sistemas dominantes de subsistencia comunitaria, y se ha relacionado la estabilidad de los términos con la importancia o "salience" de sus referentes. Aún así, la relevancia de los patrones de subsistencia con los de la nomenclatura etnobiológica todavía merece investigación, así como la idea de importancia ("salience") y su posible relación con la estabilidad terminológica. La investigación actual aborda tal relación y su variabilidad. Hacemos más preciso el concepto de estabilidad por medio de una investigacion de las frecuencias de herencia y préstamos en el vocabulario etnobiológico. Precisamos el concepto de importancia ("salience") por medio de investigaciones de la frecuencia de términos heredados y términos prestados en el vocabulario para plantas y animales que pudieran ser considerados "importantes" por distintas razones. Los resultados indican que se encuentra mas estabilidad entre los términos cuyos referentes son los elementos centrales en el sistema de consumo de comestibles (tanto si sean cultivados o recolectados). Las etiquetas para plantas o animales con propiedades psycotrópicos manifiestan una frecuencia mas alta de préstamos. No identificamos patrones distintas entre los sistemas de etiquetas para elementos cultivados en contraste de los no cultivados, ni para los sistemas para elementos involucrados en comercio, aunque observamos que los términos en la muestra con la más alta frecuencia de ser prestados tienen como referentes elementos involucrados en comercio.

1. Corresponding author. Linguistics, Yale University, 370 Temple St, New Haven, CT 06520, USA (claire.bowern@yale.edu)

2. Linguistics, Yale University, 370 Temple St, New Haven, CT 06520, USA (hannah.haynie@yale.edu)

3. Zoology, Oxford University, South Parks Road, Oxford, OX1 3PS, UK (catherine.sheard@zoo.ox.ac. uk)

4. Independent Scholar, Washington, DC, USA (barryalpher@gmail.com)

5. Linguistics, University of Texas at Austin, 305 E. 23 $3^{\text {rd }}$ Street STOP B5100, Austin, TX 78712 (pattieepps@utexas.edu)

6. Anthropology, University of Arizona, PO Box 210030, Tucson, AZ 85721-0030 (jhill@email.arizona. edu)

7. School of Language Studies, Australian National University, Canberra, ACT 0200 (patrick. mcconvell@anu.edu.au) 


\section{Introduction}

Work by Berlin (1992), Brown (2000), Urban (2010), and others has developed hypotheses regarding the structure of ethnobiological nomenclature systems and the cross-linguistic variation these systems exhibit. Systems of ethnobiological terminology are thought to be strongly correlated with the dominant means of subsistence in linguistic communities. For example, food production systems may be relevant to differences in rates of lexical replacement, following the observation that words for domesticates are subject to slower replacement than words for wild species because of their cultural salience (Balée and Moore 1991; Berlin, Breedlove, and Raven 1973).

However, the question of relevance of subsistence patterns-as well as a more general notion of "salience" - to the development of ethnobiological nomenclature calls for further investigation. Several of the above hypotheses have been developed with very limited sampling, creating a need for more systematic exploration. For example, Berlin's (1992) study, though influential, has at its core only 13 languages, seven of which are spoken in hunter-gatherer societies (five from North America). While other studies (e.g., Donohue and Denham 2009; Urban 2010) use much broader language samples, they investigate few terms. Here we evaluate hypotheses about stability in ethnobotanical nomenclature and the relationship of this nomenclature to subsistence patterns using standard lists from a large and geographically diverse sample of languages. Three hundred and eighty-five flora and fauna terms were exhaustively coded for etymology (following the methods in Bowern et al. 2011) in 130 hunter-gatherer and agriculturist languages of North America, Amazonia, and northern Australia.

This breadth of linguistic and lexical sampling allows us to conduct a relatively fine-grained exploration of the development of ethnobiological nomenclature in hunter-gatherer and agriculturist languages. We conduct an overall comparison of the stability of the flora/fauna lexicon in languages associated with these two basic subsistence patterns in order to refine the notion of "salience," what it might mean for etymological stability, and how it might interact with subsistence patterns. We compare findings across the three geographic sub-areas of our sample to investigate regional differences. Our sample includes hunter-gatherer languages in contact with agriculturists (mainly in the Americas) and those with no historical agriculturist contact (primarily in Australia), allowing for a more nuanced study of the impact of subsistence patterns on the development of this area of the lexicon. We also make comparisons between categories of flora and fauna terms that derive their salience from different cultural functions (e.g., domesticates, psychotropics, and ritual items) and compare the lexical stability of flora/fauna domains to borrowing patterns in basic vocabulary.

\section{Background}

\section{Subsistence Pattern and Ethnobiological Terms}

Recent ethnobiological work has focused on the structure of flora/fauna nomenclature systems and the variation apparent in this semantic domain 
cross-linguistically. Scholars such as Balée (2000), Berlin (1992), Brown et al. (1985), Fowler and Turner (1999), and Witkowski et al. (1981) have led the way in formulating influential conclusions about the ethnobiological systems found among hunter-gatherer groups and their comparison to agricultural counterparts. This work has resulted in generalizations about language structures that appear to correlate with the ways in which people interact with their environment.

Urban (2010) conducted an extended study of unique beginner terms across the world's languages. ${ }^{1}$ These terms, associated with the most inclusive level of ethnobiological classification, are accorded special status by Berlin (1973), who claims that they are the last level of taxonomic hierarchy to emerge in the development of an ethnobiological lexicon. Urban found clear support for the assumed correlation between "traditional" (i.e., small-scale hunter-gatherer, horticulturalist, or pastoralist) societies and the lack of terms for a unique beginner, and argues that named unique beginner ranks are most closely associated with agricultural groups. These findings carry with them implications about the relative hierarchical complexity of the ethnobiological lexicons of agriculturist languages and hunter-gatherer languages. Brown (2000) also notes, following Berlin (1992), that hunter-gather languages tend to have nonhierarchical ethnobiological nomenclature systems.

Another area in which the hierarchical organization of ethnobiological terms is claimed to differ across subsistence patterns is in the use of life-form terms in contrast to specific species terms. Authors (e.g., Brown et al. 1985) place the locus of this variation on societal complexity, claiming that as language populations become larger and more complex, more speakers lose direct contact with their environment, requiring the use of more generalized terms. This predicts that certain flora/fauna terms should be more stable than others in different types of societies. Brown (1984) also noted an effect of subsistence pattern on both the structure of plant and animal names and the overall size of ethnobiological taxonomies. Brown linked agriculturist languages with larger flora/fauna lexicons and also found them more likely to employ binomial labels in naming plants and animals. According to Brown et al. (1985), these differences in ethnobiological taxonomies can be explained by factors that render plants and animals more salient to agriculturist cultures than to hunter-gatherers, such as the creation of biodiversity through the transition to agriculture and the use of wild plants and animals to alleviate vulnerabilities of agriculturist societies like drought and illness.

While a great deal of the ethnobiological literature is concerned with the development and structure of taxonomies, the underlying question of the relative linguistic stability of flora and fauna terms has also emerged as an important area of study. The comparative study by Berlin, Breedlove, Laughlin, and Raven (1973) of flora and fauna terms in two related Maya languages, Tzeltal and Tzotzil, investigated patterns in retention and replacement. Their results demonstrated a difference in retention rates between plants of varying levels of cultural significance, for which domestication was a crucial factor. Similarly, Balée and Moore (1991) conducted a comparative investigation of five Tupi-Guarani languages, with similar results; following Berlin et al. (1973), they explain the 
positive association between degree of domestication and degree of retention as a consequence of the high cultural salience of cultivated items.

\section{Lexical Stability and Cultural Salience}

Studies like that of Berlin et al. (1973) led to the now-prevalent view that the stability of ethnobiological items relates to their cultural salience. Discussion of salience in the anthropological literature has tended to revolve around notions of ranking and the number of taxonomic levels (e.g., Atran 1987, 1998; see also Brown et al. 1986), rather than determining the relative salience of plant and animal species as otherwise defined (see below). Nonetheless, cultural salience has been put forth as an important factor in the coding of plants and animals with lexical entries (Berlin et al. 1981) and the retention of these plant and animal terms (Berlin, Breedlove, and Raven 1973).

The notion of cultural salience at the heart of this area of the literature is somewhat nebulous and sensitive to interpretation. Basic scales of cultural importance have been developed independently by several scholars to describe, rank, and sometimes even quantify this abstract variable. Most of these systems revolve around degrees of human interaction with a plant or animal (e.g., Lee 1979; Turner 1974), types of human interaction with a particular species (e.g., Berlin, Breedlove, and Raven, 1973), or combinations of these (e.g., Turner 1988) though more abstract systems such as Hunn's (1982) "activity signatures" have also been proposed.

Berlin, Breedlove, Laughlin, and Raven's (1973) scale of cultural salience is a basic classification system, assigning plant and animal species to a limited number of categories of increasing cultural importance. This scale divides species into cultivated, protected, wild but useful, and insignificant categories. While use certainly factors into this schema, the primary determinant of salience in the Berlin et al. (ibid.) system is the degree of human intervention in the production of a particular species. This contrasts with systems like the one proposed by Turner (1988), who describes cultural salience in terms of use, broadly construed. Turner's Index of Cultural Significance is organized around a number of different types of resource use (including some categories that may not involve literal use, such as mythological significance, taboo, and mere recognition). These categories of use are ranked by relative contribution to survival, with food uses and materials outranking medicines, which in turn outrank ritual and recreational uses. To this scale of usage types, Turner adds measures of the intensity and exclusivity of use, resulting in a comprehensive and quantitative measure of an item's cultural importance.

The systems that have been developed to describe cultural salience primarily focus on ranking or quantifying the salience of individual plants or animals. However, the logical inference that there is a direct relationship between the degrees of salience as measured by these systems and lexical retention rates fails to account for other cultural and linguistic facts that are relevant to lexical borrowing. New technology, for example, can be highly culturally salient but subject to linguistic innovation and renewal. Furthermore, items that are culturally salient can also be subject to cultural borrowing, which is frequently accompanied by lexical borrowing (e.g., psychotropic substances like hashish 
and coffee). Items of high cultural salience can be subject to linguistic taboo; dangerous animals, for example, can be both mythologically important and prized prey (see Burridge [2012]; Emeneau [1948]; and Simons [1982]; amongst others, for the phenomenon and its implications for reconstruction). Finally, culturally salient items are also subject to terminological specialization and differentiation. Terminological fragmentation (e.g., the appearance of many words for "cow" but no generic " $\mathrm{cow}^{\prime}$ " term in Maasai) does not have a positive effect on long-term linguistic stability, because it increases potential targets for semantic change. Thus, the relationship between salience and retention depends on broader cultural and historical contexts, and may vary among different domains of use. These issues have not been addressed in the previous literature on ethnobiological nomenclature, which takes an uncritical view of salience.

This study probes the relationship between salience and stability, and the variability within this relationship. We refine the notion of stability by studying both inheritance rates (that is, how frequently a word is etymologizable to a proto-language) and loan rates. We also track rates of "unique" vocabulary (that is, terms without known etymologies). We refine the notion of "salience" by separately testing retention and loan rates in flora and fauna vocabulary that might be considered salient (or not) for different reasons. We hypothesize that ethnobiological terms associated with survival uses are more likely to be stable; that is, to show fewer loan instances and for the terms to be more frequently assignable to a proto-language. We predict lower stability rates in flora/fauna items associated with tool use, in line with literature (e.g., Haspelmath and Tadmor 2009) which points to greater loans in material culture. We also expect low stability in psychotropic plants because of their regional importance and importance for trade (see, for example, Sherratt 1995). Finally, we predict that loan levels of traded items should be elevated. As we discuss below, some of these predictions are borne out while others, such as those to do with trade, are not.

We take a different approach in investigating differences between huntergatherer and agriculturist ethnobiological lexicons than do authors such as Brown (2010). We make no attempt to date changes. Rather, we investigate changes in the lexicon in terms of patterns of borrowing and inheritance as functions of flora/fauna type, geographic region, and subsistence pattern.

\section{Investigation into the Structure of Hunter-Gatherer Ethnobiological Systems}

\section{Language Sampling}

For the current study, flora and fauna terms were collected and coded for etymology in 130 languages in three study areas: 1) northern Australia, 2) North America, and 3) South America. This set of study areas parallels those used in other studies (e.g., Bowern et al. 2011) and builds upon the set of basic vocabulary items gathered for that work in 105 of the sample languages. The selection of these study areas was based on several considerations. First, these regions are all home to numerous hunter-gatherer groups. The North and South American study areas also include agriculturist languages, though this contrast in subsistence pattern is not available for Australia, where no indigenous 


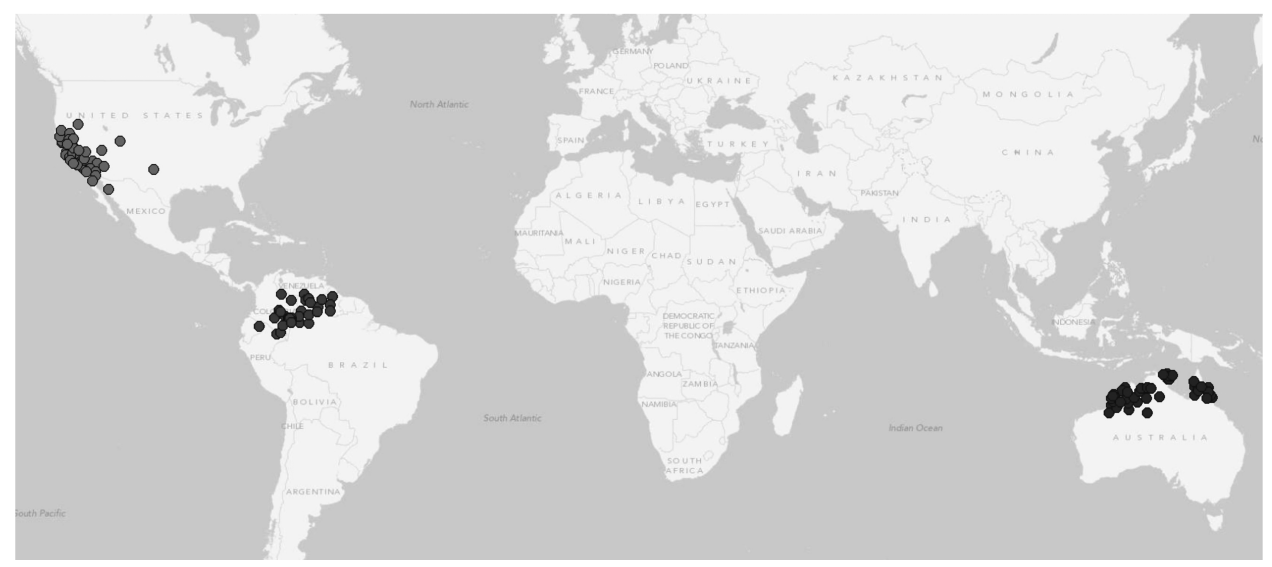

Figure 1. Case study areas and languages.

agriculture existed. In addition to the geographic diversity introduced by sampling languages from three continents, these study areas also provide a high degree of linguistic diversity. At least five language families and four linguistic isolates are represented among the North American languages in the sample, eight families and two isolates in South America, and nine families in Australia. A map of the sample languages is given in Figure 1.

Practical considerations also make these three study areas suitable for this investigation. In each of these areas we were able to assemble sizeable samples of well-attested languages for which good documentation-and in particular good documentation of plant and animal terms-exists. Furthermore, the authors possess specialist knowledge about these three areas, which is crucial for the accurate etymological analysis of forms.

The Australian language sample comprises 52 languages from the Kimberley region, Arnhem Land, and Cape York Peninsula. Among these languages are members of the northernmost Pama-Nyungan subgroups as well as their nonPama-Nyungan neighbors. All of the languages in this sample are associated with hunter-gatherer subsistence patterns.

The North American sample includes 46 languages of California and the Great Basin. This sample excludes languages north of the Sacramento River valley, which limits the ecological range of the study area and eliminates the influence of families such as Athabaskan and Algic. Eight of the languages in the sample had speaker communities who practiced some cultivation of food plants. These are the Uto-Aztecan languages Cahuilla, Chemehuevi and Comanche, and the Yuman languages Cocopa, 'Iipay Aa, Mojave, Yavapai, and Yuma. The remaining 38 languages were spoken by hunter-gatherers, although intensive management of wild plants has been recorded for these groups (Anderson 2005).

The South American language sample draws on 32 languages, the bulk of which are found in the northwest part of the Amazon basin. These languages are found in a region encompassing parts of Colombia, Peru, Ecuador, and Venezuela. A range of subsistence strategies is found in this study area, leading to a roughly equal division between languages spoken by peoples with a relative 
hunting-gathering focus, and those with a more agricultural orientation. We note that defining groups as either hunter-gatherer or agriculturist is often not straightforward, particularly in the Amazon basin, where almost all groups rely on some mix of hunting, fishing, and small-scale agriculture for subsistence. In these contexts, we classified groups on the basis of whether a majority of their caloric intake comes from foraging activities, and whether they have a defined cultural focus as foragers/trekkers in the regional context (for discussion of these issues see, for example, Pozzobon 1991; Rival 2002). Overall, two-thirds of the languages of the Americas in the sample come from groups for whom hunting and gathering can be considered a primary subsistence focus.

Lexical items were retrieved from dictionaries where available, supplemented by grammatical descriptions and archived field notes as needed. ${ }^{2}$ Sources for lexical items are listed in the supplementary materials. Terms were reconstructed using the comparative method (Hock and Joseph 1996) and coded for etymology in the manner described in Bowern et al. (2011). This coding scheme created a basic division between four categories: 1) loaned, 2) inherited, 3) unique, and 4) semantic shift. The loaned items category includes those items identified as loans, where the loan has occurred after the split of the language from its nearest neighbor. In other words, loans into a proto-language are not counted as loans in all descendent languages that contain reflexes. Inherited items are classified as those that can be reconstructed to an earlier stage of the language with the same meaning. Words that can be reconstructed to an earlier stage of the language with a different meaning are classified as instances of semantic shift. Finally, unique terms are those that have no identifiable source internally or in any neighboring languages. This category contains words replaced through various word formation processes outside the focus of this study.

In South America but also to a certain extent in North America, the etymological coding is complicated by the nature of the linguistic sample and the availability of information about linguistic relationships. Both of these case study areas contain many small language families, and particularly in South America existing work on historical reconstruction is in some cases inadequate. These factors limit our own application of the comparative method in coding inheritances and borrowings in certain cases. Thus, it is possible that we have failed to identify all loans among genetically related languages in these study areas. However, this weakness is neutralized somewhat by the fact that many of the contact situations in Amazonia, and to a lesser extent North America, take place across language families. Additionally, we have compared across many languages not included in the immediate sample, which further raises the likelihood of loan detection. For example, the 32 South American languages have been compared systematically against more than 65 other languages from the same and surrounding regions.

\section{Flora/Fauna Sampling}

Work such as Berlin's (1992) has focused on languages with fairly complete ethnobiological descriptions. This approach is of limited application, however. First, the relevant data simply do not exist for many languages of the world. For those that do have published lexical materials, there is often no way to evaluate 
the quality and accuracy of description of flora and fauna nomenclature, since most linguists' biological training is very limited. For the many hunter-gatherer languages that have become extinct over the last hundred years, there is no possibility for either gaining more information or, in most cases, evaluating the ethnobiological information recorded in existing materials. Shifts in human experience and the loss of biological diversity in the twentieth century have led to rapid loss of flora and fauna knowledge in North America (Nabhan and St Antoine 1993), and a similar situation can be expected in Australia and South America. The chance of finding the requisite data in dense language samples for the areas under study is nearly zero. Dense coverage is required to study loan interaction, but appropriate datasets do not exist and cannot now be created.

In this research we have taken a different approach. Rather than attempt to exhaustively sample from the flora/fauna domain, we surveyed approximately 125 terms for common flora/fauna items within each of the areas under study. ${ }^{3}$ The survey terms are balanced among orders and taxa within each area, and were sampled for a range of sizes, functions, cultivation status, and salience. The lists included both life-form ("bird," "tree") and species terms to allow some investigation of claims of stability in different hierarchical levels of ethnobiological nomenclature. ${ }^{4}$ Term lists were also roughly matched between case study areas, to allow for comparison between areas that have very little overlap in precise species; that is, similar numbers of terms within each life-form designation were studied for each area. The use of species rather than varietals in the list of terms allowed for better comparison across study areas. We allowed very limited substitutions for closely related species and varietals to further increase the comparability of forms across study areas. ${ }^{5}$

Overall, the set of items used for this study includes 100 floral and 285 faunal terms, of which 129 are relevant for Australia, including 22 floral terms; 122 total terms apply in the North American study area, including 32 floral terms; and 138 of these items are found in South America, including 46 floral terms. The balance between flora and fauna was affected by overall availability of reliable data for these items, but the composition of the lexical sample is offset by the care we have taken to balance the list among taxa and compare patterns within flora and fauna subsets. ${ }^{6}$

Terms were coded for use category, size of item, flora/fauna subdomain (e.g., mammal, reptile), and whether they are life-form terms. The "use" category coding classified each term as belonging to or not belonging to several categories associated with our hypotheses about use, salience, and lexical replacement. These categories are: dangerous items, domesticated items, eaten items, medicinal items, items of mythological or ritual importance, psychotropic substances, and traded items. Several of these categories-specifically, eaten, medicinal, and dangerous items-derive varying levels of cultural salience from their survival functions. Other categories, such as mythological or psychotropic items, are salient for other reasons that may impact the likelihood of their replacement. These reasons include their centrality to the cultures concerned and their importance for regional interactions. The domesticated items category, in addition to its expected cultural salience, relates directly to subsistence activities. Finally, the economic function of trade items may endow them with cultural 
significance, but the importance of this category is also related to the hypothesis that trade itself is likely to influence loan rates, because of the interaction across groups that it entails. Coding for these uses was performed using specific information from ethnographic materials, where available, and generalized from available sources when no specific ethnographic descriptions of a particular item's use in a particular culture were available. For example, some smaller Australian language groups have no ethnographic descriptions, but where other ethnographies describe a practice as very widespread, we ascribe the use to the area, including groups for which we have no direct evidence. Where usage is mixed within an area, we do not generalize across groups.

Effects of ethnobiological nomenclature hierarchies on item names were largely ignored in the creation of our dataset. We did not control for whether a language uses a varietal or specific term for a particular item in the list. Rather, we used the most common term that is used for that item. We recognize that this has the potential to introduce inconsistencies, but our data lack enough specificity to resolve these matters completely. We are also unable to account for underdifferentiation and overdifferentiation by the researchers who produced the data sources we drew from, because few terms for closely related species are included in our list. However, this is unlikely to affect our results.

\section{Statistical Methods}

All statistical analyses were performed using R 2.13.1 Statistical Software. A simple linear regression was used to test the correlation between basic vocabulary and flora/fauna loan rates. Because etymological patterns vary substantially by region and by language family - a pattern qualitatively evident in the data and confirmed by an ANOVA test-and because the purpose of this study is to examine patterns across all three regions, we used generalized linear mixed models (GLMM, computed using the package nlme [Pinheiro et al. 2012]) to test the significance of etymological patterns. As such, all linear models had case study area as a random effect, and the analyses (discussed below) also had language family nested as a random effect within the case study areas. Finally, to satisfy the requirement of a linear model, all etymology proportions were increased by 0.01 and log-transformed.

\section{Results}

\section{Loan Rates among Languages}

Loan rates in flora/fauna vocabulary are nearly always significantly higher than those in basic vocabulary in the same languages (Bowern et al. 2011). This is as expected given cross-linguistic tendencies for differences in loan rates across semantic domains (e.g., Hock and Joseph 1996:261). Loan rates in basic vocabulary and flora/fauna are strongly correlated ( $\mathrm{r}=0.7, \mathrm{p}<0.001)$, implying that the same social processes might be at work in both domains (see below, however, for further discussion). Figure 2 plots loans in 204 words of basic vocabulary and the loan rates in flora/fauna vocabulary for each of the languages in the case study. Comparison of the curves of loan frequencies across case study areas also indicates a high degree of similarity between basic vocabulary and flora/fauna vocabulary. ${ }^{7}$ 


\section{Loan Rates by Language}

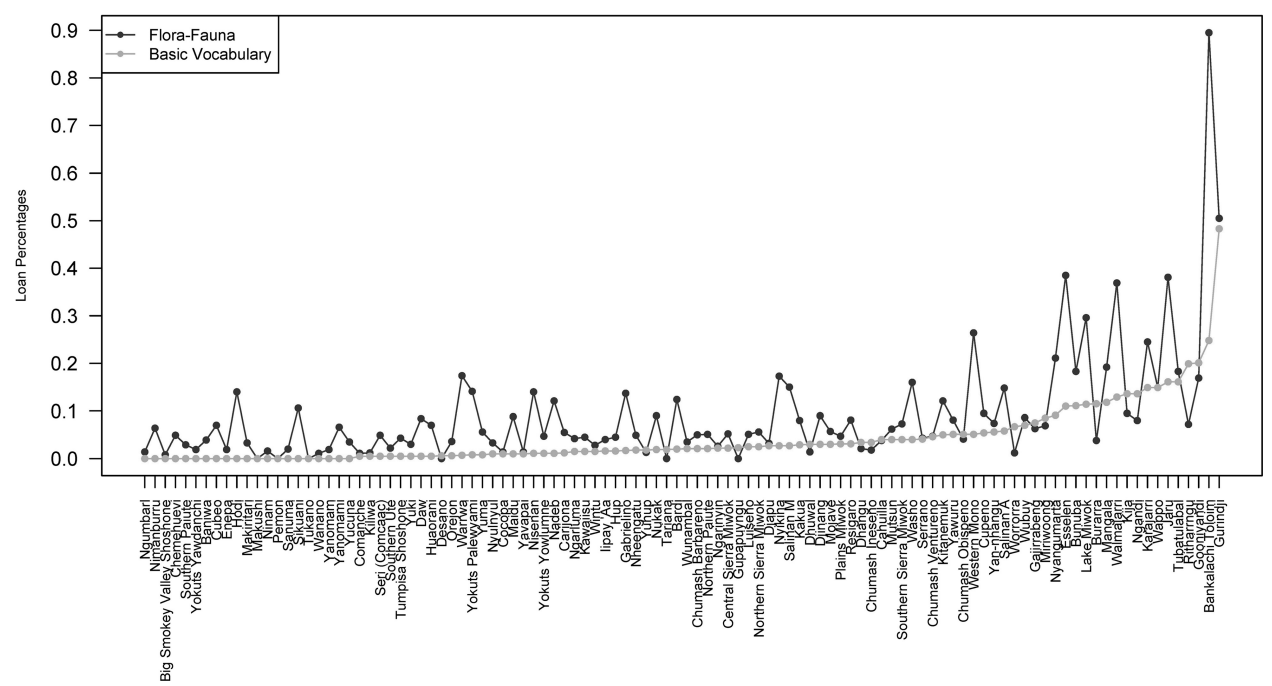

Figure 2. Loan rates by language.

A few languages had higher loan rates in basic vocabulary than in flora/fauna. Notable exceptions to loan rate tendencies described above include Ritharrngu (where the flora/fauna loan count is $7 \%$, but basic vocabulary is at $20 \%$ ) and Burarra (3.8\% flora/fauna, $11.5 \%$ basic vocabulary). In both languages, the loan rates for basic vocabulary are substantially higher than for flora/fauna terms. It is not known at this stage what might be the cause of exceptions to the trends. It is notable, however, that the few languages with sizable discrepancies between basic vocabulary and flora/fauna borrowings are from the Australian case study area, and most are spoken in Arnhem Land. ${ }^{8}$ There are two outlier languages in North America (Bankalachi-Toloim and Tübatulabal) and three in Australia, all from the Ngumpin-Yapa subgroup of Pama-Nyungan (Gurindji, Jaru, and Walmajarri), where loan rates are exceptionally high in both flora/fauna and in basic vocabulary.

Because loan rates differ by case study region (ANOVA, $p=0.003$ ), with higher rates in Australia and lower rates in Amazonia, as well as by language family (ANOVA, $p=0.006$ ), all subsequent analyses were computed using a linear mixed model with case study region and language family as nested random effects. That is, we first controlled for variation in case study area and language family before looking at any other potential source of variation. Figure 3 shows the loan rates by case study area.

With those controls in mind, hunter-gatherer communities show significantly higher loan rates compared to agriculturists (GLMM, p < 0.0001), as well as higher levels of unique items (GLMM, p = 0.0154) and lower levels of inherited items (GLMM, p = 0.0251). "Unique" items refers to words without traceable etymology. Note that while one might ascribe these results to hunter-gatherer languages being relatively understudied historically (and therefore with fewer etymologies available), it is not the case that hunter-gatherer languages in our case study regions are less well attested than the agriculturist languages. ${ }^{9}$ 


\section{Loans by Case Study Area}

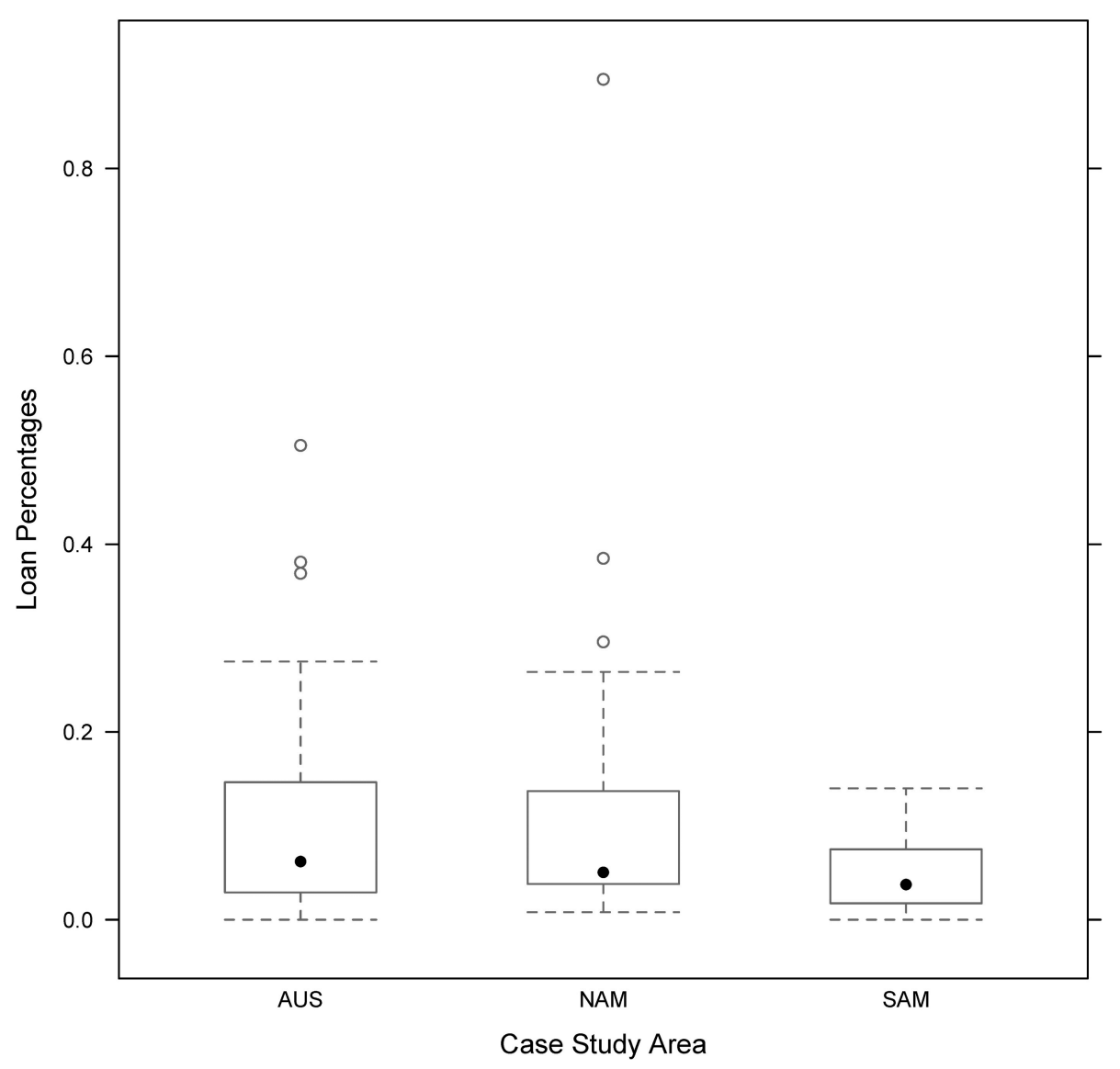

Figure 3. Loan frequencies for languages, grouped by case study area. AUS = Australia; NAM = North America; SAM = South America.

There was a clear overall difference in loan rates between hunter-gatherers and agriculturists (see also Table 1). It is unclear, however, whether that difference stems from (a) the relative importance to those language speakers of the different types of flora and fauna considered in the study, or (b) social asymmetries within agricultural and hunter-gatherer groups and the way they interact with their environments, which in turn lead to differences in the flora/fauna nomenclature system. In case (a), we might expect a region like Amazonia to be more uniform (but different from other parts of the world), since most groups practice varying degrees of agriculture and foraging. That is, we would not expect as much difference between agriculturist and hunter-gatherer groups in Amazonia, where both types of groups interact with both wild and cultivated species. If $(b)$ is the case, we might expect differences between hunter-gatherers and agriculturists in Amazonia because of the way in which those groups use food production as a way to classify societies. We note (see below) that cultivated species themselves are not 
Table 1. Descriptive statistics; (top) overall and by case study area; (center) overall and by subsistence mode (including Australian data); (bottom) overall and by subsistence mode (excluding Australian data).

\begin{tabular}{|c|c|c|c|c|}
\hline & All & AUS & SAM & NAM \\
\hline Minimum & 0.0 & 0.0 & 0.0 & 0.1 \\
\hline Mean & 9.8 & 11.6 & 4.89 & 11.4 \\
\hline Median & 6.5 & 8.0 & 3.75 & 6.7 \\
\hline Maximum & 89.5 & 49.5 & 14.0 & 89.5 \\
\hline \multicolumn{2}{|c|}{ Borrowing rate (includes AUS) } & All & HG & AG \\
\hline \multirow{4}{*}{\multicolumn{2}{|c|}{$\begin{array}{l}\text { Minimum } \\
\text { Mean } \\
\text { Median } \\
\text { Maximum }\end{array}$}} & 0.0 & 0.0 & 0.0 \\
\hline & & 9.8 & 11.5 & 3.5 \\
\hline & & 6.5 & 7.2 & 2.9 \\
\hline & & 89.5 & 89.5 & 10.3 \\
\hline \multicolumn{2}{|c|}{ Borrowing rate (excludes AUS) } & All & HG & AG \\
\hline \multicolumn{2}{|l|}{ Minimum } & 0.0 & 0.0 & 0.0 \\
\hline Mean & & 8.9 & 11.3 & 3.5 \\
\hline \multicolumn{2}{|l|}{ Median } & 5.9 & 7.0 & 2.9 \\
\hline \multicolumn{2}{|l|}{ Maximum } & 89.5 & 89.5 & 10.3 \\
\hline
\end{tabular}

Note: AUS $=$ Australia, SAM $=$ South America, NAM $=$ North America, HG $=$ Hunter-Gatherer, AG = Agriculturalist.

a source of differences between the groups. Testing this hypothesis further is beyond the scope of this paper, since at this point we lack the required sample size of Amazonian languages to investigate this in more detail. However, the Amazonian results do suggest that the region's hunter-gatherer languages have borrowed more flora/fauna terms than have the agriculturist languages. This observation is in keeping with option (b), and it is known that prestige differences between at least some hunter-gatherers and agriculturists have fostered one-way bilingualism and borrowing (e.g., Epps 2009). However, it does not rule out option (a), since some hunter-gatherers may have increased their reliance on horticulture fairly recently, which could also lead to more loans (see Epps in press).

Aspects of population demography were tested for significance using the same characteristics that appear in Bowern et al. (2011). Exogamy, population size, and population density all showed significant predictive value in at least one etymological category, with exogamous groups having fewer loans, mediumsized groups the highest rate of unique items, larger groups the highest rate of inheritance, and medium-dense groups the lowest rate of inheritance but the highest rates of unique items and loans.

Urban (2010) identified several demographic correlations for unique beginner terms; we did not find the same correlations, however, which suggest that linguistic processes may affect different ethnobiological terms in different ways. Urban (2010:218) found that societies with the smallest populations tended to lack unique beginner terms, for example. ${ }^{10} \mathrm{We}$ should note that all the societies considered in this study would be considered "small" in most surveys, with all but three groups in South America having populations of fewer than 5,000 individuals. Nor do we find the same patterns that drive loans in basic vocabulary. Bowern et al. (2011) found that mobility was a significant predictor 
Table 2. Significance of demographic traits.

\begin{tabular}{llll}
\hline Demographic aspect & Loan rate & Unique items & Inheritance \\
\hline Exogamy & $\boldsymbol{p}=\mathbf{0 . 0 0 0 2}$ & NS $(p=0.07)$ & NS $(p=0.24)$ \\
Mobility & NS $(p=0.20)$ & NS $(p=0.18)$ & NS $(p=0.17)$ \\
Population size & NS $(p=0.24)$ & $p=0.035$ & $p=0.0206$ \\
Population density & $p=0.021$ & $p=0.022$ & $p=0.0376$ \\
\hline
\end{tabular}

Note: NS = not significant; significant results appear in boldface.

of loan levels in basic vocabulary, though this is not significant for flora/fauna vocabulary.

The patterns reported in Table 2 are puzzling and in many cases unexpected; for example, it is not clear why exogamy should predict fewer loans, when it increases the opportunities for language contact through both multilingual individuals and by creating opportunities for multilingual interaction. Indeed, exogamy was a significant predictor of high loan levels in basic vocabulary. However, if flora/fauna words are particularly associated with individual groups, they might serve as a signal of group identity and thus borrowing might be impeded in situations where group affiliation is reliably and frequently signaled through language, as is the case where linguistic exogamy is high. We have no explanation for the population density results, however, why they should be significant for flora/fauna vocabulary but not for basic vocabulary. It is possible that broad demographic characteristics of populations are masking other effects. Roberts and Winters (2012) provide a number of cautionary examples of robust but clearly spurious correlations between social and linguistic variables and point out the difficulties of working with demographic patterns when links are causally intuitive.

\section{Patterns in Borrowing Domains}

The figure below gives the overall pattern of loan rates by species in each of the three case study areas. As shown in Figure 4 and Table 3, most flora/fauna items are not loaned. Table 3 gives the loan rates overall and by case study area for each flora/fauna item.

The most frequently loaned word in all three case study areas was the word for 'horse' (Equus caballus L.), with loan rate of $100 \%$. As an acculturation term, its high loan status is unsurprising (see, for example, Brown 1999:21). Note that we did not specifically examine introduced flora and fauna in this study, although we recognize that loanwords are not the only strategy used to refer to acculturation items in the case study areas.

Within North America, the most frequently loaned items (apart from horse) are datura, wild oats, chia, and tobacco. Datura (Datura wrightii Regel) and tobacco (Nicotiana of several species) are both psychotropic plants, with important religious uses in indigenous California. Tobacco plants were closely managed in most groups (see Hill 2011 for a detailed discussion of the loanword complexes). Wild oats (Avena fatua L.) is an introduced plant that was incorporated into a cuisine that made substantial use of wild grass seeds; the term in California languages is nearly always a loan from Spanish. Chia (Salvia columbariae Benth.) yields a highly nutritious grain that also had medical uses. 


\section{Item Loan Frequency, Grouped By CSA}

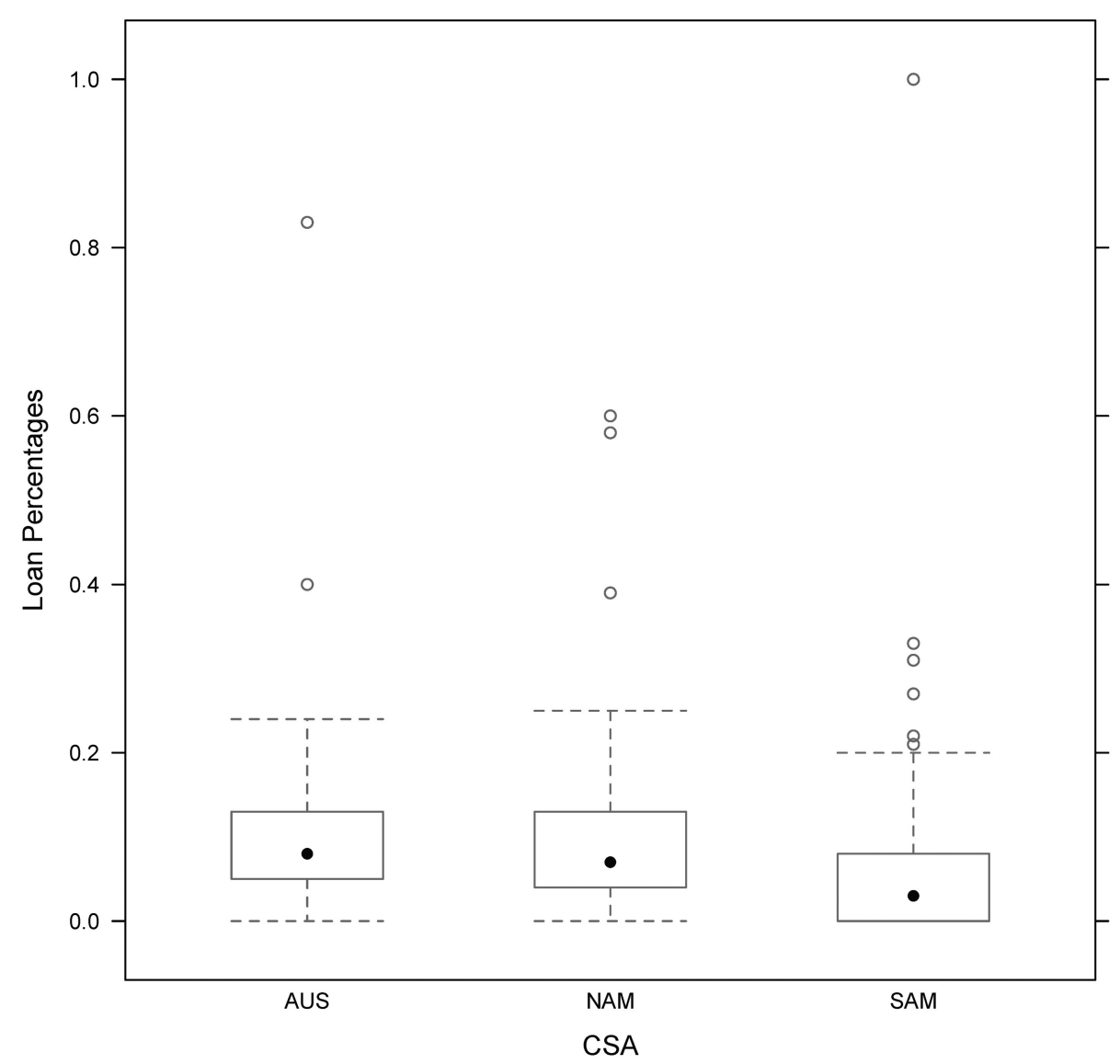

Figure 4. Item loan frequency in each case study area. AUS = Australia; NAM = North America; SAM $=$ South America.

Chia was used both as a ceremonial offering and in trade (Lightfoot and Parrish 2009), and stands of the plant were carefully managed (Anderson 2005).

The most frequently loaned items from Australia (besides horse) are: pearlshell (40\% of attestations are loans), red river gum (Eucalyptus camaldulensis Dehnh., 24\% loans), bat (23\%), freshwater crocodile (Crocodilus johnstonii Krefft, $23 \%)$, and witchetty grub (22\%). Pearlshell is a highly traded item across the north of Australia (Akerman and Stanton 1994). The red river gum is loaned in a

Table 3. Borrowing rate statistics by item.

\begin{tabular}{lllll}
\hline & All & AUS & SAM & NAM \\
\hline Minimum & 0.0 & 0.0 & 0.0 & 0.0 \\
Mean & 0.08 & 0.09 & 0.06 & 0.09 \\
Median & 0.06 & 0.08 & 0.03 & 0.07 \\
Maximum & 1.0 & 0.8 & 1.0 & 0.6 \\
\hline
\end{tabular}

Note: AUS $=$ Australia, SAM $=$ South America, NAM $=$ North America. 
cluster of languages in the Victoria River District and Kimberley regions of the Northern Territory/Western Australia, where six contiguous languages have borrowed the term from one another. The motivations for borrowing this term are unclear at present, given that there is no evidence that the tree (which is widespread across Australia) arrived recently in the area. Terms for freshwater crocodile are borrowed into the Nyulnyulan languages from neighboring Pama-Nyungan languages. ${ }^{11}$ Bowern (2007) has argued that speakers of Nyulnyulan languages recently spread east, adopting names for newly encountered species from their Pama-Nyungan neighbors. The borrowing of crocodile is an example of this.

For South America, certain domesticates and psychotropics top the loan list. Several of these are Wanderwörter-widespread in particular areas. Terms for coca (Erythroxylum coca Lam.) are particularly frequent loans, though sporadically attested in the sample (67\% [73\% if doubtful loans are included], attested for 15 languages). Banana (Musa sp., 18\% [32\% if doubtful loans included]) and maize (Zea mays L., 18\% [29\% if doubtful loans included]) are also relatively likely to be borrowed. These are followed in the list of flora loans by the hallucinogen Banisteriopsis caapi Morton, the domesticates beans (Phaseolus spp.) and pineapple (Ananas comosus (L.) Merr), and the rubber tree (Hevea sp.). All of the domesticates are relative latecomers and/or not central members of the Amazonian crop inventory, of which the key elements are the less-frequently loaned manioc, chili pepper, tobacco, and others. The rubber tree, while native, was the focus of an intensive extractive industry following European contact; such a radical change in salience has been documented elsewhere as a motivation for borrowing (see below, and Balée 2003). Of fauna, terms for iguana (Iguana sp., 43\% [48\% if doubtful loans included]) are strikingly widely borrowed, with cockroach, duck, and agouti further down the list; motivations for borrowing these terms are not currently known.

The most stable items (that is, the items most commonly coded as 'inherited' in the case study areas) are varied. For North America, they include 'skunk', 'valley live oak', 'pinyon pine', and 'grey ground squirrel'. For South America, the most stable items are 'hummingbird', 'South American tapir', 'hot pepper', 'tree', and 'bee'. The Australian case study area shows fewer highly stable items; those with the highest scores are 'fish', 'mosquito', 'dugong', 'tree', 'crow', and 'centipede'. Note that heritability statistics are not directly comparable across case study areas because the number of families and language isolates varies substantially. The implications of inheritance for notions of 'stability' are discussed below, particularly in relation to genericity in the Australian example.

\section{Borrowability and Heritability by Subcategory}

Items vary extensively in their borrowability and heritability when cultural category ('mythology', 'danger') is considered. These categories were designed to reflect different aspects of cultural salience and significance. Dangerous items are culturally salient because they loom large in culture and pose a threat to the safety of the community. Eaten items are significant for the opposite reason: rather than threatening the safety of the community, they provide sustenance. Likewise, medicinal items are salient because of their powers of healing (though they may also be esoteric knowledge). Items of mythological or ritual importance are embedded in the culture and thus have salience in how they reflect a group's 
Table 4. Inheritance figures.

\begin{tabular}{|c|c|c|c|c|c|c|}
\hline Category & $\mathbf{N}$ & Loan & Inherited & Unique & Semantic shift & \\
\hline \multirow[t]{3}{*}{ Psychotropic } & 5 & $<0.001 \mathrm{M}$ & $<0.001 \mathrm{~L}$ & 0.19 & 0.65 & \\
\hline & & $<0.001 \mathrm{M}$ & $<0.001 \mathrm{~L}$ & 0.81 & 0.51 & $\mathrm{HG}$ \\
\hline & & $0.004 \mathrm{M}$ & 0.20 & 0.11 & 0.66 & $\mathrm{AG}$ \\
\hline \multirow[t]{3}{*}{ Medicinal } & 22 & 0.70 & 0.51 & 0.65 & 0.12 & \\
\hline & & 0.21 & 0.94 & 0.92 & 0.95 & $\mathrm{HG}$ \\
\hline & & $0.08 \mathrm{~L}$ & 0.53 & 0.99 & $0.09 \mathrm{~L}$ & $\mathrm{AG}$ \\
\hline \multirow[t]{3}{*}{ Traded } & 30 & 0.28 & 0.67 & 0.23 & 0.92 & \\
\hline & & 0.99 & 0.99 & 0.99 & 0.69 & $\mathrm{HG}$ \\
\hline & & 0.28 & 0.79 & 0.22 & 0.68 & AG \\
\hline \multirow[t]{3}{*}{ Dangerous } & 25 & $0.08 \mathrm{~L}$ & 0.36 & 0.41 & 0.12 & \\
\hline & & 0.45 & 0.45 & 0.70 & 0.68 & $\mathrm{HG}$ \\
\hline & & 0.18 & $0.09 \mathrm{M}$ & 0.41 & $0.09 \mathrm{M}$ & $\mathrm{AG}$ \\
\hline \multirow[t]{3}{*}{ Eaten } & 184 & 0.61 & $0.02 \mathrm{M}$ & 0.76 & 0.11 & \\
\hline & & 0.62 & $0.04 \mathrm{M}$ & 0.45 & $0.006 \mathrm{~L}$ & $\mathrm{HG}$ \\
\hline & & 0.20 & 0.17 & 0.23 & 0.52 & $\mathrm{AG}$ \\
\hline \multirow{3}{*}{ Mythological } & 38 & 0.98 & $0.09 \mathrm{M}$ & 0.98 & 0.34 & \\
\hline & & 0.23 & $0.08 \mathrm{M}$ & 0.28 & $0.03 \mathrm{~L}$ & $\mathrm{HG}$ \\
\hline & & 0.30 & $0.09 \mathrm{M}$ & 0.95 & 0.33 & $\mathrm{AG}$ \\
\hline \multirow{3}{*}{ Life-form } & 40 & 0.38 & $0.03 \mathrm{M}$ & 0.50 & $0.004 \mathrm{M}$ & \\
\hline & & 0.29 & 0.31 & 0.95 & 0.45 & $\mathrm{HG}$ \\
\hline & & 0.23 & 0.18 & 0.97 & 0.77 & $\mathrm{AG}$ \\
\hline \multirow[t]{3}{*}{ Domesticated } & 15 & 0.69 & 0.58 & 0.10 & 0.18 & \\
\hline & & 0.69 & 0.64 & 0.93 & 0.14 & $\mathrm{HG}$ \\
\hline & & 0.61 & 0.71 & 0.59 & 0.15 & $\mathrm{AG}$ \\
\hline
\end{tabular}

Note: $\mathrm{HG}=$ hunter-gatherer; $\mathrm{AG}=$ agriculturalist; $\mathrm{M}$ = significantly more likely to hold for that category; $\mathrm{L}=$ significantly less likely to hold for that category; significant results appear in boldface.

worldview. Domesticates are argued to be salient (at least to agriculturist groups) because of the central role of agriculture in social organization and subsistence.

Here, we discuss the whole data set, then address differences between hunter-gatherer and agriculturist groups. Summary data are given in Table 4. Some patterns emerged in the data as a whole, but not in HG or AG groups individually. In each cell, the first number is the overall result, the second is the AG groups only, and the third is the HG groups only. The tag M following a significant result indicates that the condition is significantly more likely to hold for the category, while $\mathrm{L}$ indicates that it is less likely to hold. ${ }^{12}$ As loan, inheritance, and unique item rates vary significantly (ANOVA, $p=0.002, p<$ $10^{-15}$, and $\mathrm{p}=0.007$, respectively) by case study area, each of these analyses is held constant by case study area.

\section{All Data}

Psychotropic items are more likely to be loaned and less likely to be inherited. These results hold also for agriculturist groups; hunter-gatherers show the former but not the latter. These findings are interesting from the point of view of Sherratt's work, particularly Sherratt (1995). First, though Sherratt (1995:1) points out that the rigid distinction between "drugs" and "food" that many Western post-industrial cultures (including English speakers) make is not a universal, our findings point to a significant etymological difference between the two categories, and in particular a special status of psychotropic substances as diffusible across culture areas. Sherratt's own work highlights the importance of such substances in 
"consumption rituals" (Sherratt 1995:4) and notes the instability of certain cultural practices associated with psychoactive substances, particularly kava in the Pacific and alcohol and opium in England. The psychotropic substances in our sample, particularly tobacco (Lightfoot and Parrish 2009:348) and pitchuri (Duboisia hopwoodii F.Muell.) (Johnston and Cleland 1933), are widely traded in their regions. We presume that terms for psychotropics behave differently from other consumables because of their high desirability, which leads to rapid and pervasive spread. As seen below, however, trade overall was not a significant predictor of borrowability. Psychotropics may also be important in ritual and mythology, adding to their cultural salience, although note again that mythology was not a significant predictor of loanhood alone.

Traded items: There was no significant interaction in the data set. This was unexpected, since it contradicts both intuition and known individual cases of words such as 'coffee' and 'tea' (which are both widely traded and loaned; see e.g., Dahl 2011). Moreover, several of the most highly loaned items in the dataset are also widely traded (e.g., pearlshell in Australia and chia in California). These results suggest that trade alone, particularly for items with a long history of use, is not enough to imply loanhood. Some widespread modern trade items with high loan status, such as 'coffee' and 'tea', are also addictive substances. It may be that because so many items are traded in areas like Amazonia that sampling like this does not reveal true patterns. Alternatively, it may be that trade, overall, really does not have a significant single effect on loan likelihood, given the number of other factors which may lead to loanhood. Finally, it may be that certain traded items are specializations by particular communities, but have been around for a very long time, and may have been more generally produced in the past (however, specialization is not for the most part tied directly to resource accessibility, at least not in the northwest Amazon). The issue of traded items is discussed further below.

Eaten items: Items associated with survival were significantly more likely to be inherited. This finding is consistent with previous studies (e.g., Berlin 1973; Brown et al. 1976) that imply that culturally central items will have stable nomenclature. The effect was found both overall and in the agriculturist groups but not in the sample of hunter-gatherer languages.

Dangerous items: Poisonous or dangerous flora/fauna were less likely to be loaned. In the hunter-gatherer dataset alone, they also showed a greater tendency to be inherited and to undergo semantic shift. This latter fact may be associated with the widespread practice of taboo replacement and euphemism (what Burridge [2012] has called "protective euphemisms"13) associated with dangerous animals. It is, perhaps, surprising that this effect was significant only in the hunter-gatherer groups, since many of the best attested cases of protective euphemisms associated with animals come from agriculturist societies. Consider, for example, the taboo deformation of words for 'wolf' and 'bear' in the IndoEuropean family (Watkins 2000:xxvi). Protective euphemism should also lead to less rather than greater etymological stability.

Mythological or other ritually significant terms were more likely to be loaned but the effect was above the threshold for significance. When not controlling for area, mythological items did show a significant $(\mathrm{p}=0.008)$ tendency to be loaned among hunter-gatherer groups. However, this result was 
likely primarily driven by high loan psychotropic items like tobacco in the North American sample.

Life-form terms: Unique beginner and life-form terms were more likely to undergo semantic shift. This may reflect some ambiguity in the sources, where items were glossed as more general than their reference in the language in fact denotes. It may, however, be a real phenomenon within the data. It is found in the 'fish' 'meat' polysemy in Australia, for example, as described in McConvell (1997). McConvell describes cases where a word undergoes semantic change from a generic term to a specific term for the most common species in an area. The reverse change is also found. Within our sample, semantic shift was significantly more likely when considering the full dataset, but was not significant in either AG or HG groups alone.

Terms with generic reference were also more likely to be inherited, though again this effect was not seen in HG or AG groups when considered independently. These results suggest that such terms are, on the whole quite stable (though when changing, subject to change by semantic shift). The stability of such terms across the sample is interesting in the light of claims by Brown et al. (1976) that such terms are of recent origin in hunter-gatherer languages. We find no evidence for recent adoption of these terms. One term for 'bird', jurlak (and related forms), is most likely a Wanderwort, but is not a recent spread. It has clearly been borrowed across a large number of both Pama-Nyungan and nonPama-Nyungan languages in northeastern Australia, but shows too many sound changes to be a recent loan. Generic terms were missing in some hunter-gatherer languages in the sample. In Australia, for example, it is known that languages differ in the number of life-form terms they have. Wati and Karnic languages, for example, tend to lack a generic term for 'snake' (though having a proliferation of terms for individual species), while such a term is found in most Kimberley languages. Because of the difficulties in determining whether a term is genuinely not found in the language or simply not recorded, we treated all such data as "missing." If Brown et al. (1976) are correct, however, we would expect those languages that have terms to have innovated them recently, and therefore not to show strong inheritance patterns in this category. Our results imply that a more detailed study of life-form terms would be profitable.

Domesticates: One might expect terms for domesticates to be more prone to borrowing by hunter-gatherers (see below for further discussion of this point) since, by definition, they lack community-internal agricultural resources. We might alternatively expect domesticates to be culturally salient both among agriculturists and among hunter-gatherers, though for different reasons. Domesticates are considered culturally salient in agriculturist communities because of their central role in group survival (a category, as seen above, which does show significant etymological stability). In hunter-gatherer groups, however, domesticates might be considered salient because they are worth trading for. However, cultivated flora/ fauna overall do not show any significant trends in our sample. We subsequently considered cultivated flora only-they were significantly more likely to be inherited or unique, and less likely to be loaned or to have undergone semantic shift. That is, all etyma categories showed significant skewing and there is some support for the centrality of cultivated flora stability (perhaps as related to in-group survival). ${ }^{14}$ 
Table 5. Flora and fauna subsets.

\begin{tabular}{|c|c|c|c|c|c|}
\hline Category & $\mathbf{N}$ & Loan & Inherited & Unique & Semantic shift \\
\hline \multirow[t]{3}{*}{ Flora } & 100 & 0.9 & 0.67 & 0.9 & 0.24 \\
\hline & & 0.11 & 0.34 & 0.07 & 0.9 \\
\hline & & 0.94 & 0.25 & 0.5 & 0.9 \\
\hline Fauna & 285 & & & & \\
\hline \multirow[t]{3}{*}{ Bird } & 80 & 0.29 & 0.84 & 0.48 & 0.22 \\
\hline & & 0.35 & 0.9 & 0.2 & 0.16 \\
\hline & & 0.06 & 0.08 & 0.9 & 0.13 \\
\hline \multirow{3}{*}{ Mammal } & 62 & 0.2 & $0.001 \mathrm{M}$ & $<0.001 \mathrm{~L}$ & 0.62 \\
\hline & & 0.6 & 0.1 & 0.003 & 0.2 \\
\hline & & 0.28 & 0.02 & $<0.001$ & 0.53 \\
\hline \multirow[t]{3}{*}{ Reptile } & 27 & 0.8 & 0.37 & 0.5 & 0.7 \\
\hline & & 0.007 & 0.4 & 0.6 & 0.73 \\
\hline & & 0.6 & 0.6 & 0.6 & $0.053 \mathrm{M}$ \\
\hline \multirow[t]{3}{*}{ Fish } & 14 & 0.28 & 0.67 & 0.41 & $0.03 \mathrm{~L}$ \\
\hline & & 0.6 & 0.3 & 0.25 & $<0.001$ \\
\hline & & 0.26 & 0.26 & 0.09 & $<0.001$ \\
\hline \multirow[t]{3}{*}{ Plant } & 61 & 0.73 & 0.94 & 0.55 & 0.9 \\
\hline & & 0.2 & 0.5 & $0.05 \mathrm{M}$ & 0.9 \\
\hline & & 0.53 & 0.43 & 0.95 & 0.47 \\
\hline \multirow[t]{3}{*}{ Tree } & 39 & 0.55 & 0.55 & 0.36 & $0.01 \mathrm{M}$ \\
\hline & & 0.5 & 0.6 & 0.8 & 0.9 \\
\hline & & 0.31 & $0.029 \mathrm{M}$ & 0.29 & $0.002 \mathrm{M}$ \\
\hline \multirow[t]{3}{*}{ Sea creature } & 30 & 0.7 & $<0.001 \mathrm{~L}$ & $0.004 \mathrm{M}$ & 0.17 \\
\hline & & 0.3 & 0.6 & 0.7 & $<0.001 \mathrm{~L}$ \\
\hline & & 0.53 & $0.03 \mathrm{~L}$ & 0.09 & 0.8 \\
\hline \multirow[t]{3}{*}{ Insect } & 63 & $<0.001 \mathrm{~L}$ & 0.31 & $0.001 \mathrm{M}$ & 0.29 \\
\hline & & 0.002 & 0.3 & 0.006 & 0.8 \\
\hline & & $<0.001 \mathrm{~L}$ & 0.3 & 0.001 & 0.35 \\
\hline \multirow[t]{3}{*}{ Small } & 144 & 0.63 & 0.2 & 0.09 & 0.13 \\
\hline & & 0.12 & 0.01 & $0.03 \mathrm{M}$ & 0.3 \\
\hline & & 0.8 & 0.4 & 0.07 & 0.06 \\
\hline \multirow[t]{3}{*}{ Large } & 64 & $0.03 \mathrm{M}$ & 0.39 & 0.51 & 0.07 \\
\hline & & 0.5 & 0.6 & 0.19 & 0.4 \\
\hline & & $0.03 \mathrm{M}$ & 0.5 & 0.16 & 0.4 \\
\hline
\end{tabular}

Note: $\mathrm{M}$ = significantly more likely to hold for that category; $\mathrm{L}$ = significantly less likely to hold for that category; significant results appear in boldface.

Flora and Fauna: Table 5 gives the results for different types of flora and fauna. No significant differences were found between flora and fauna in the dataset, though unique terms among agriculturists approached significance for flora. Terms for mammals were significantly both less likely to be unique and more likely to be inherited; this result probably has to do with the general importance of mammals as objects of the hunt and sources of food within the sample. ${ }^{15}$ The lack of loans in insect terminology is intriguing. The significantly unique status of insect terms may reflect their general lack of "usefulness," resulting in frequent replacement and, similarly, little relevance in cross-linguistic interactions (we note that while some insects are regularly eaten in these regions, most of those included within our sample are not).

A few tendencies were noted with respect to the size of items: small animals were more likely to be unique among agriculturists, while large animals (relative to each category of birds, mammals, reptiles, etc.) were more likely to be loaned both overall and among hunter-gatherers (though the effect was not found for agriculturists). This result contradicts that discussed by Ehret (2011:90), who 
finds for Africa that terms for large wild animals tend to be resistant to borrowing. Ehret provides no quantitative evidence for his claim, however.

\section{Hunter-Gatherers Only}

When considering just the data from languages spoken by hunter-gatherers in the sample, trends tend to mirror those of the overall sample. Psychotropic substances, for example, show the same degrees of loan likelihood as in the general sample, and several patterns that were at marginal significance in the general sample are statistically significant in the hunter-gatherer sample; the loan status of mythological items and the inheritance likelihoods for generic life-form terms are two examples. Semantic shift tendencies for dangerous items are also constant between the two samples, but there are exceptions to the overall correlations between the samples. Traded items are less likely to be unique $(\mathrm{p}<$ 0.05) in the hunter-gatherer sample, while no effect was seen in the combined sample. Since our nomenclature list is fairly short, this may reflect the relative importance of items on the list to hunter-gatherers.

Mythological or ritually significant terms showed significant inheritance levels in the hunter-gatherer sample, but not the general sample, when not controlling for area. In the hunter-gatherer sample, mythological terms were both more likely to be loaned and more likely to be inherited (the flip side of being less likely to be unique; items in this category fall more clearly into the two classes: some loaned, some inherited), than other items in the sample. These patterns are best explained in light of the notion of cultural salience discussed above-the importance of mythological terms for a given group over time is likely to promote their retention within that group's language on the one hand, and their transmission between groups (and languages) in contact situations on the other.

\section{Case Study Area Comments}

Since the number of languages in each area is quite small, statistical tests that compare data subsets lack power. However, we can offer qualitative comments on the case study areas. In the North American sample, data quality is elevated by triangulating between modern dictionaries, with high-quality phonological representations but often with very general definitions (for instance, 'kind of bird'), and the availability of extensive word lists for flora and fauna collected in the early part of the twentieth century by the distinguished zoologist C. $\mathrm{H}$. Merriam, ${ }^{16}$ who recorded data in an eccentric English-based orthography but provided species (and sometimes even varietal) identifications that in most cases are highly accurate and specific. From notes in Merriam's lists that occasionally indicate "not shown," one can infer that he was showing informants examples, perhaps taxidermic specimens or preserved skins, and dried herbarium specimens for plants. For the important Chumashan group of languages, Timbrook (2007) was able to recover plant names and good identifications from the fieldnotes of John P. Harrington. However, data quality varies among the languages, and in some cases many terms are missing.

Within the South American sample, the relatively low flora/fauna loan rates are consistent with the general paucity of loanwords observed in these languages, as noted above. Also in keeping with cross-regional trends noted 
here, South American hunter-gatherer languages tend to have higher flora/fauna loan rates, although agriculturist and hunter-gatherer languages occur at both ends of the loan-rate spectrum. In comparison to the South American sample as a whole, the Tukanoan, Arawak, and Nadahup languages of the Vaupés region exhibit relatively low loan rates, in keeping with local practices disfavoring language mixing among agriculturists and hunter-gatherers alike (see Epps 2009, and above); however, the rates in the hunter-gatherer languages Kakua and Nukak are surprisingly high, perhaps indicating a somewhat weaker integration into Vaupés sociolinguistic practices. ${ }^{17}$ The languages exhibiting the highest numbers of flora/fauna loans include several hunter-gatherer languages. Hodii (isolate) and Sikuani (Guahiban) top the list, with significant numbers of loans (about 14\%), predominantly from Carib and Arawak languages, respectively. Nadëb and Dâw_-both Nadahup languages spoken outside the Vaupés—also show relatively high loan rates, mostly from Arawak. It is noteworthy that lexical borrowing in the South American hunter-gatherer languages is predominantly one-way, with agriculturist languages as donors. Partial exceptions to this generalization are Sikuani and Piapoco (Arawak), where loanword exchange has gone in both directions (though loans into hunter-gatherer Sikuani still outnumber those going the other way), and Kakua, which has apparently absorbed some loans from Hup, another hunter-gatherer language. The agriculturist languages with the largest numbers of attested flora/fauna loans (close to 11\%) are Cubeo (East Tukanoan) and Resígaro (Arawak), both known to have extensive interaction with Arawak and Bora speakers, respectively (see for example, Chacon in press; Seifart 2011).

The Australian case study area has a sizable number of words for which there is reason to suspect loanhood but where the direction is unknown. There are 225 such loans in the sample, compared with 453 likely loans and 46 doubtful loans. The direction of borrowing cannot be identified because of the absence of diagnostic sound change or morphology which would provide a clue to the donor language. Eighteen of the words in the Yawuru (Nyulnyulan) list, for example, are shared with either Mangala or Karajarri, neighboring PamaNyungan languages. In the Yawuru case, some of the words show reduplication (cf. rurdururdu 'hornet', yinyjiyinyji 'praying mantis'). Reduplication is not a common pattern in inherited flora/fauna vocabulary in Nyulnyulan languages, but it is more common in Marrngu languages. This may provide a clue to the direction of borrowing. Where loan direction can be identified, however, the exchange goes in both directions (at least for the Nyulnyulan/Pama-Nyungan border languages).

\section{Status of Life-Form Terms and Polysemy}

The survey set contained a number of terms that refer to ranks higher than the species or folk generic level, either life-form or unique beginner terms. There were some difficulties in inferring the true status of these words in our lexical data. In some languages, it was unclear whether the word was truly a life-form term, or simply the term for the most common species or genus in the area. In some languages there is genuine polysemy here. For example, Bardi garrjarl refers to both the life-form 'frog' and specifically the green tree frog, Litoria caerulea Myers (Bowern 2012). In several of the North American languages, the 
word for 'rattlesnake' (species other than the sidewinder) is also a generic word for 'snake'. In other cases, the sources are unlikely to be fully accurate. Furthermore, we are often unable to distinguish languages that genuinely lack life-form or unique beginner terms from those where such terms were simply not recorded. In the Dhay'yi (Yolnu, Australia) list, for example, words for 'tree', 'snake', 'ant', and 'kangaroo' are missing. The presence of such terms in closely related Yolyu varieties, however, makes the absence of the Dhay'yi words most likely due to recording gaps rather than absence from the Dhay'yi language. In other cases, however, we cannot be so certain. We do not therefore present quantitative results for this area, but we note variability in the presence, absence, and substance of life-form categorizations across our study areas. In Australia, for example, 'snake' generics are present in the north but are missing from a number of Pama-Nyungan subgroups in the Central regions. Others have a generic that covers only poisonous snakes. Some northwest Amazonian languages likewise make a basic distinction between snakes that are associated with biting and/or venom vs. those associated with constriction and/or lack of venom. No South American language in our sample has an attested generic for 'insect', and many lack a generic term for 'ant'; on the other hand, generic 'fish' and 'bird' terms appear to be widely attested (but we note that in two cases- the hunter-gatherer languages Hup and Ninam-'bird' is a compound involving the generic 'game animal'). In North America, a generic for 'insect' is attested for only 11 of 46 languages, but other probable generics from our lexical sample are widely attested. In Australia, 'insect' terms are rare and when they are attested, they have diverse etymologies ranging from loans, such as Karajarri jurru 'insect', to semantic shift (e.g., Kurtjar eeny, cognate with *minya ${ }^{18}$ 'meat'), to unique items such as Gumatj wuyuwuyu. The Nyulnyulan term juurru (from which the Karajarri term is borrowed) has different meanings in different Nyulnyulan languages. In Eastern Nyulnyulan and Nyulnyul, it covers both 'biting insects', such as mosquitoes, and larger dangerous biting creatures such as snakes and sharks. It is most commonly glossed as 'critter'. In Bardi, the 'critter' meaning is lost and the term is used only for snakes and sharks. Its most common meaning is 'snake', but the phrase gaarrayoon joorroo (literally 'joorroo from the sea') can be used if disambiguation is required.

Some life-form terms are polysemous with items that are not part of the flora/fauna domain. Fairly common in Australia, for example, is polysemy between the word for 'bone' and words meaning 'shell'. The unique beginner 'tree' is usually also polysemous with 'stick' or 'wood'. Several of the North and South American languages also exhibit polysemous 'wood-tree', and many South American languages exhibit polysemy between '(tree) bark' and '(human/ animal) skin'.

We also have examples of semantic shift where a generic, life-form, or unique beginner term in one language is a species level term in related languages. Central Australian kathi, for example, means 'ant' in some languages but 'animal' in others. In the sample, semantic shift appears to be relatively more prevalent in the Australian case study region than either of the Americas, though this may be due to misidentification in some of the more poorly attested languages. Semantic shift is also found between species and is attested in all case study regions. For 
example, cognates of Tariana pidú 'giant otter' (Pteronura brasiliensis Gmelin) mean 'Neotropical otter' (Lontra longicaudis Olfers) in other members of the Central North Arawak subgroup. In Australia, Ngumbarl jibilyurru 'duck' is cognate with Bardi jiibily 'grebe' (Tachybaptus novaehollandiae Stephens). Overall, semantic shift accounts for only a small number of total changes in the lexical sample, with 156 etyma showing the change over all three case study areas.

\section{Further Discussion}

\section{Why Should Flora/Fauna Loan Rates be Greater than Basic Vocabulary?}

That basic vocabulary is relatively resistant to borrowing is a standard axiom of historical linguistics, and relates to these terms' frequency in discourse, their comparable existence across languages, their cultural familiarity, and other factors. It is likewise well known that other semantic domains exhibit more variable rates of replacement and innovation through borrowing (e.g., Haspelmath and Tadmor 2009; Tadmor et al. 2010). ${ }^{19}$ A number of factors may foster borrowing of flora and fauna terms in ways that are less likely to be relevant for basic vocabulary. For example, where the presence of different plants and animals across regions varies with ecological zones (e.g., coastline, desert, mountains), languages spoken in those zones may lack the respective words in their lexicons. When speakers move to a new region and develop new familiarities and dependencies on the local flora and fauna, they innovate new terms accordingly-often by borrowing from neighboring languages. Similarly, the development of interaction and trade patterns that bring new entities into regions where they were previously unknown can lead to comparable borrowing events.

Changes in cultural and subsistence practices may also foster the adoption or renewal of flora and fauna terms, even where these had already existed in a given language's lexicon. Where patterns of use for particular plants and animals are subject to innovation, this can lead to prestige- or need-driven borrowing as the innovation spreads. These processes are especially likely to affect domesticates and psychotropics, but changes in prominence for non-cultivated food sources or ritually relevant species may also result in lexical borrowing, particularly where these changes are facilitated by interaction among language groups. In such cases, we note that an increase in cultural salience may in fact encourage lexical replacement by borrowing, in contrast to the association between long-term salience and lexical stability over time (see above; and see Berlin, Breedlove, and Raven, 1973). For example, the borrowing of both domesticated and wild 'cacao' terms in the Amazonian language Ka'apor, as discussed by Balée (2003), was apparently driven by the importance of domesticated cacao as an export crop within the Jesuit missiondriven regional economy of the eighteenth century. This phenomenon may also account for several 'rubber-tree' loans within our South American sample.

Finally, flora and fauna terms may also be prone to replacement deriving from other kinds of cultural significance, notably taboos and cultural showmanship. Taboo is of course a well-known motivation for lexical innovation, and often applies to potential predators or ritually significant animals such as bears or jaguars (see above, for example, the loan of 'jaguar' from Tupi-Guarani in Nadëb [South America] could plausibly be attributed to taboo). There is 
likewise some evidence from South American languages that the cultural practice of showing off one's hunting ability may foster lexical replacement of certain animal terms; this occurs via the generation of synonym sets relating mostly to medium to large mammals, as Fleck and Voss (2006) investigate in the Panoan language Matses. Similar patterns are found in other regional languages as well, such as Kulina (Arawá) and Dâw (Nadahup), although borrowing appears to play a minimal role in these innovations.

\section{Loan Rates and Social Factors}

As discussed above, the broad demographic factors identified in basic vocabulary borrowing did not appear to be relevant for flora/fauna borrowing, even though overall loan rates were correlated. The functional motivation for loaning a word may vary greatly across semantic domains. In flora/fauna, for example, loans often enter languages when speakers come into contact with a new item for which they do not have a term. Also as noted above, however, this is rarely (if ever) the case for basic vocabulary, since the borrowing replaces an existing term rather than creating a new one. We might expect a certain base percentage of flora/fauna loans to be due to the same social processes as give rise to loans in other domains (including prestige borrowing, taboo replacement, and assimilated code switches) while others would be the result of factors particular to the domain, such as needing a word for a newly encountered item.

As we have shown, some of the highest loan rates in basic vocabulary were associated with languages in the process of shift: both shift toward the donor language (e.g., Bankalachi/Toloim) and shift away from the donor language(s) (e.g., Gurindji) were associated with outlier loan levels. The same languages have high loan levels in flora/fauna. One might assume that if speakers are shifting away from a language, they might not acquire vocabulary in specialist domains such as ethnobiology. The association with language shift, however, may not hold more generally. For example, though Aka and Baka Pygmies have shifted from their original languages to Bantu and Ubangian languages respectively, they share approximately $20 \%$ of vocabulary, much of which is in specialized semantic domains such as flora and fauna and marriage (Bahuchet 2012). In this case, flora/fauna terminology has been retained.

\section{Hunter-Gatherers and Structure of the Ethnobiological Nomenclature System}

None of these speculations explains the robust difference between loan rates in hunter-gatherer and agriculturist groups, however. While loan rates were substantially higher for hunter-gatherers, there was also more variation. The standard deviation for agriculturist groups was 0.027 , while for hunter-gatherers it was 0.121. This implies that agriculturists are more uniform than huntergatherers, and the relevant explicandum is not why hunter-gatherer loan levels are so high, but rather what makes agriculturists more uniform. One possible explanation relates to Brown's (1984:46) observation that hunter-gatherers may tend to have less elaborate flora/fauna lexicons overall than do agriculturists, which would predict that hunter-gatherers who come into contact with agriculturists may augment their lexicons through this cultural contact, whether by innovation or by borrowing (however, we note that this possibility does not seem to be supported by our results, in which Australian hunter-gatherers-who 
have no contact with agriculturists-have higher flora/fauna loan rates than do North and South American hunter-gatherers, who do interact with farmers). If the difference between basic vocabulary and flora/fauna loan rates were higher in the Americas than in Australia, this might provide support for this hypothesis. Mean borrowing rates are 7\% higher for Australia, 6\% for North America, and $4 \%$ for South America. In all case study areas, the standard deviation is higher for flora/fauna loans than for loans in basic vocabulary, but while it is only $2 \%$ higher in Australia, it is 10\% higher in North America (and 3\% in South America). Another possible explanation is that the unbalanced prestige relations that typically pertain between hunter-gatherers and their agriculturist neighbors (e.g., Peterson 1978) would favor borrowing into the hunter-gatherer languages, rather than vice versa.

\section{Order of Introduction of Life-Form Terms}

Brown (1984) provides evidence that life-form terms appear in languages in a sequence, where terms for bird, fish, and snake are found before terms for mammal and 'wug' (worm + bug). This implies that we may find variation in stability of life-form terms. It is likely that the presence and stability of these terms is also related to a combination of their relative cultural salience, as well as to the number of species that are found within the category in the region. The relationship here is not straightforward, however. For example, one might make the argument that languages such as those of the Yolyu subgroup of PamaNyungan lack a life-form term that distinguishes 'mammals' from other animals ${ }^{20}$ in part because the region where the languages are spoken is relatively poor in mammal species compared to, for example, the number of fish. However, that argument would not apply in the case of the Central Australian languages that lack a life-form term for 'snake' or 'reptile', despite those species being abundant in the region. It would also not explain why 'mammal' terms are rare more generally across Australia.

The most stable life-form terms in the data occur in the South American case study region. They include the terms for 'tree', 'bat', 'fish', 'snake', and 'bird'. Within Australia, the only comparably stable life-form term was 'fish', which is found in a large set of Pama-Nyungan languages and is readily reconstructible. ${ }^{21}$ Terms for 'tree' and 'ant' were also relatively stable. Within the North American area, 'tree', 'frog', and 'fish' were the most stable terms.

As noted above, a life-form term for 'insect' was missing from all South American languages. Australian and North American vocabularies also tended to be missing this term but it is unclear whether this is because the languages lack such a term or whether it was not salient to the English-speaking linguists who recorded the languages and who therefore did not ask for a term. For instance, generic 'insect' or 'bug' was not included in the elicitation instruments used by the zoologist C. H. Merriam with languages of California and the Great Basin. Other terms with high levels of missing data were 'beans' and 'horse' (South America; note that horses are largely absent from the region, and therefore are not included in most dictionaries), 'shark' and 'stingray' (Australia; though present in the coastal languages so this level of missing data is skewed by the relatively large number of inland languages in the sample), and 'snake' 
(Australia; missing in part because of the languages which lack this life-form term).

The term for 'bird', was stable in the North and South American case study regions. In Australia, however, it was (along with 'kangaroo' and 'bat') one of the most frequently loaned life-form terms. One term was frequently loaned among the Marrngu and Nyulnyulan languages of coastal Western Australia, while a second term was found (also extensively loaned) to the east of those languages. The loan patterns show that terms for 'bird' in Australia have undergone several independent loan events.

The life-form terms also showed substantial numbers of unique etyma (though not significantly more than other categories). The 'insect' life-form term was most frequently unique in North America. South American 'caterpillar' and Australian 'goanna' life-form terms were also frequently unetymologizable. In the Australian case, the lack of reconstructibility is probably caused by shifts between a generic term for 'goanna' and the common species, Varanus gouldii Gray, which may also have a specific name. Overall, however, there is nothing that seems to unite the life-form terms that show exceptionally high (or exceptionally low) levels of unique data.

\section{Cultivars and Stability}

To reiterate, cultivar terms might be expected to be particularly resistant to borrowing, on the one hand, because of their cultural salience (see Balée and Moore 1991; Berlin, Breedlove, Laughlin, and Raven 1973), but only for as long as they have been important for that group's subsistence. On the other hand, where they have only recently attained cultural importance-especially where this came about via group interaction-cultivar terms may be more likely to exhibit borrowing. In our sample, terms for domesticated plants showed no significant difference in loanword status compared to the rest of the lexicon, both across and within the American case study regions. It is possible that this finding has to do with relatively lower vs. higher loan rates among cultivars between agriculturist and hunter-gatherer languages, but unfortunately there are not enough data points to test this difference statistically. However, there is at least some anecdotal evidence that cultivars show relatively high rates of innovation and borrowing among hunter-gatherers, most notably within the Nadahup family (see Epps in press); see also the high loan counts among particular domesticates and psychotropics in South America (compare above). On the other hand, most South American groups that depend heavily on hunting and gathering do depend on agriculture to some degree as well, and this dependence appears in most cases to be old-at least predating the breakup of subgroups into individual languages. Finally, we note that a comparison of heritability in cultivar terms among regions and case study areas is not straightforward because of the wide range of time-depths among families and subgroups across our sample.

\section{Biodiversity Effects within and between Regions?}

The case study areas examined here exhibit different degrees of ecological variability. In the northwest Amazon region, variability in biodiversity is not 
extensive; all languages sampled are spoken in inland regions with multiple waterways, relatively low elevation, and tropical rain forest, although there are some differences relating to size of waterways, soil type, access to highlands, and presence of savannah. In contrast, biodiversity for the North American sample is striking. The sample includes languages from the Pacific Coast, from the California Central Valley, from the Sierra Nevada, and from the inland desert regions. The Australian sample also includes considerable variation in biodiversity, from desert regions to tropical rain forest. As noted above, differences across regional ecological zones are often tied to different levels of biodiversity, and these differences could plausibly foster lexical borrowing of flora and fauna terms as groups move or trade between zones. However, with a few exceptions (such as a few words for marine fauna), the lexical sample chosen for each of the three regions was designed to be as general as possible, in order to maximize comparability.

It is also known that languages spoken in regions of relatively high ecological diversity and species richness have larger inventories of ethnobiological nomenclature (e.g., Maffi 2005), and there may be a relationship between the number of distinctions made in a semantic field and its relative stability. For example, if there are more distinct terms within a field, there is more opportunity for semantic shift. Unfortunately, we have no data on whether regional biodiversity could affect the results within our sample in this regard. Because the terms in our dataset are all relatively abundant in their areas, we are very unlikely to have this as a confounding effect; however, it also means that we cannot investigate this question at this point.

\section{Further Considerations}

A few caveats are warranted. Ideally, a survey such as this would include complete ethnobiological nomenclature systems across broad regions. However, exhaustive surveys are not feasible here, because data have not been gathered for too many of the languages. Our survey list was constrained not only in length but in composition. The lists were biased towards commonly occurring species in each region in order to increase the likelihood that terms would be recorded. However, because of this bias, we are unable to test the interaction of relative abundance with etymological stability. It is possible that species of relatively high abundance may be more salient and therefore more etymologically stable. Conversely, it may be that rare species may be more highly prized, and thus fulfill a special cultural niche. The ecologies of our survey regions vary internally and thus a general measure of abundance for each survey item for each area is not possible.

It is possible that loan counts may be higher in some languages than in others because of the difficulty of identifying loans between closely related languages. The careful application of the comparative method should allow the identification of loanwords in many contexts, which would minimize this problem overall. However, it does mean that for any individual word, it may be difficult to tell in the absence of a diagnostic sound change whether an item is a loan or not. It may also potentially affect some language families more severely than others, depending on the amount of interaction that has taken place among related or unrelated languages, and 
because our ability to distinguish family-internal loans from cognates may depend on the amount of comparative data from sister-languages that are available.

\section{Conclusion}

Our results support the general notion that the stability of ethnobiological terms is associated with the cultural salience of their referents. However, the relationship between cultural importance and etymological stability is revealed to be quite complex through the comparison of flora/fauna vocabulary in huntergatherer and agriculturist languages and across categories of cultural use.

The etymological inheritance which we associate with stability is significantly more common in only a small number of the categories of flora and fauna that we might otherwise expect to be culturally significant. Overall, we find a tendency toward stability in eaten items, which supports the link between survival uses, cultural importance, and lexical stability. Differences between hunter-gatherer and agriculturist groups in the strength of the eaten-inherited relationship and the explanations required to understand stability of cultivated flora terms point to the complex interplay between language, culture, and history in determining the stability of even the most frequently conserved flora/fauna terms.

The association of several categories of cultural significance with a greater likelihood of lexical borrowing shows the flip side of the cultural saliencestability link. Under certain historical and social conditions, cultural salience promotes instability. This pattern is illustrated by the contrast between items that are traded and psychotropic items. Whereas trade alone does not appear to predispose lexical items to loanhood, the combination of cultural diffusion and ritual use of psychotropic substance makes those items more likely to be loaned in both hunter-gatherer and agriculturist languages. We must conclude that the cultural importance of these items, perhaps in combination with trade, increases the loan likelihood in this case.

Lexical stability in ethnobiological terminology is a multifaceted phenomenon. Cultural salience is an important determiner of flora and fauna term stability, but the gradient scales of importance that have traditionally been used to characterize it (for example by Berlin, Breedlove, Laughlin, and Raven 1973; and by Turner 1988) are not able to capture its variable association with inheritance or loanhood. For salient items, particularly those whose use is peripheral to eating and basic survival, cultural and historical context can affect etymological outcomes associated with cultural importance.

\section{Notes}

${ }^{1}$ Unique beginner is the highest level rank in taxonymic systems (cf. English 'plant'). Other terms include 'life-form' (e.g., 'tree'), generic (e.g., 'oak'), specific, and varietal. See further Berlin, Breedlove, Laughlin, and Raven 1973).

${ }^{2}$ We acknowledge the critical points of Medin and Atran (1999:5) that competence in ethnobiological nomenclature might vary extensively across speakers of a language and that different speakers may have different systems. The terms in our list are all common terms and are likely to be known by all speakers of a language. 
${ }^{3}$ We note that this 125-term flora/fauna list is itself contextualized within a much larger list that includes basic vocabulary terms, words for material culture items, etc.

${ }^{4}$ Our survey data do not allow us to distinguish in many cases between species terms and varietals, as the glossing of terms in the lexicons of the areas is frequently insufficiently precise at this level.

${ }^{5}$ For instance, for "Pinyon pine," in the California languages in the NAM sample the species is Pinus monophylla Torr. and Frém. However, for a few languages in the sample spoken further east in the Great Basin, the species is Pinus edulis. The labels for the two species are identical in the Uto-Aztecan languages and all were coded as "Pinyon pine."

${ }^{6}$ Full lists of terms used and the languages and sources is publicly available at http:// dev.laits.utexas.edu/huntergatherer/public/home.

7 Basic vocabulary and flora/fauna loan rates were also significantly different $(\mathrm{p}<0.05)$ for each case study area taken individually (Australia $p=0.025$, North America and South America both $\mathrm{p}<0.001$ ).

${ }^{8}$ We hypothesize that flora/fauna items are most extensively borrowed when speakers migrate to a new area. We cannot conclude, however, that low loan rates for flora/fauna mean that groups have not migrated, tempting as it might be. Bowern et al. (2011) noted that the highest rates of borrowing in basic vocabulary involved cases of language shift. Given the high rates of multilingualism and exogamy in Arnhem Land, where both Ritharrngu and Burarra are spoken, language shift may be involved, though evidence is unclear. Moreover, in this area, flora/fauna terms have clan associations and so might be subject to anti-borrowing pressures that do not apply to basic vocabulary. See McConvell (2009) for a parallel argument from the Eastern Ngumpin languages of the Kimberley and Victoria River districts in northern Australia.

9 Resistance to borrowing is reported in many Amazonian hunter-gatherer languages (see Epps [2009] and Aikhenvald [1996] for examples) and also in Athapaskan (Rice 2004:340).

${ }^{10}$ Because we are working with dictionary data, we are often unable to tell whether a term is absent from a source because it is absent from the language, or simply not recorded. This was a sufficient confound for unique beginner terms that we were unable to investigate them systematically.

${ }^{11}$ Outside the survey area, the term warrij 'freshwater crocodile' has also been borrowed from a Mirndi language into Pama-Nyungan languages of the region.

${ }^{12}$ Bonferroni corrections would indicate that at the 5\% error level we should be looking for significance values at $<0.0065$. However, since these tests are dependent, the level is probably higher.

${ }^{13}$ As noted by Emeneau (1948), protective euphemisms have several motivations, including the desire not to call up something dangerous and not warning prey animals during a hunt.

14 This follows work by Epps (in press) that investigates patterns of etymological asymmetries involving cultivated plant species in the Nadahup language family of 
Amazonia. In this hunter-gatherer family, cultivar terms are shown to have undergone more innovation and borrowing, and are less likely to be inherited, than terms for useful non-cultivars. We did not, however, find this pattern extending to all hunter-gatherer families in our sample.

${ }^{15}$ Boster et al. (1986) studied correspondences between Western Linnaean classification systems and two groups of Jivaroan languages and found greater agreement in classification with non-passerines than passerines. They suggest that this is the result of greater difficulty in telling passerine specimens apart. We expect similarity in appearance between species to have some impact on etymological stability (because of the possibility for semantic change) but have no way to test this with the current data.

16 The C. Hart Merriam Papers, archived at the Bancroft Library of the University of California, Berkeley, can be accessed and read online at: http://archive.org/details/ bancroft_chartmerriam_1556_13.

${ }_{17}$ We note that Nukak speakers are now located outside the Vaupés region, but ethno-historical accounts and the presence of loanwords from Cubeo and other East Tukanoan languages are evidence that they were located within the region several generations ago (see also Politis 2007:30). Loan rates among East Tukanoan languages may be somewhat higher than they appear, due to the difficulty of detecting borrowings within this closely related group.

18 The asterisk is used in linguistics to denote a form which is reconstructed to a protolanguage.

${ }^{19}$ We note, however, that the borrowing patterns among the flora and fauna terms examined in Haspelmath and Tadmor (2009) are not directly comparable to those investigated here. Their sample focuses on generics and on 'zoo' animals, which are not native to most of the regions considered, whereas ours is almost exclusively concerned with animals and plants native to the continents on which the respective languages are spoken.

20 Yolnu languages have a term warrakan' which includes mammals and birds, but not fish, reptiles, or insects.

${ }^{21}$ However, although a generic term for 'fish' is readily reconstructible, it also shows frequent shifts in polysemy, as McConvell (1997) shows.

\section{Acknowledgments}

This work was funded by NSF grant BCS-0902114 "Dynamics of Hunter-Gatherer Language Change."

\section{References Cited}

Aikhenvald, A. Y. 1996. Areal Diffusion in Northwest Amazonia: The Case of Tariana. Anthropological Linguistics 38:73-116.

Akerman, K., and J. Stanton. 1994. Riji and Jakuli: Kimberley Pearl Shell in Aboriginal Australia. Northern Territory Museum of Arts and Sciences, Darwin, NT.
Anderson, K. 2005. Tending the Wild: Native American Knowledge and the Management of California's Natural Resources. University of California Press, Berkeley, CA.

Atran, S. 1987. The Essence of Folkbiology: A Reply to Randall and Hunn. American Anthropologist 89:149-151. 
Atran, S. 1998. Folk Biology and the Anthropology of Science: Cognitive Universals and Cultural Particulars. Behavioral and Brain Sciences 21:547-569.

Bahuchet, S. 2012. Changing Language, Remaining Pygmy. Human Biology 84:1, 11-43

Balée, W. 2000. Antiquity of Traditional Ethnobiological Knowledge in Amazonia: The Tupí-Guaraní Family and Time. Ethnohistory 47:399-422. doi:10.1215/00141801-47-2399.

Balée, W. 2003. Historical-Ecological Influences on the Word for Cacao in Ka'apor. Anthropological Linguistics 45:259-280.

Balée, W. L., and D. Moore. 1991. Similarity and Variation in Plant Names in Five TupiGuarani Languages (Eastern Amazonia). Bulletin of the Florida Museum of Natural History 35:209-262.

Berlin, B. 1973. Folk Systematics in Relation to Biological Classification and Nomenclature. Annual Review of Ecology and Systematics 4:259-271.

Berlin, B. 1992. Principles of Ethnobiological Classification. Princeton University Press, Princeton, NJ.

Berlin, B., J. S. Boster, and J. P. O'Neill. 1981. The Perceptual Basis of Ethnobiological Classification: Evidence from Aguaruna Jívaro Ornithology. Journal of Ethnobiology 1:95108.

Berlin, B., D. E. Breedlove, R. Laughlin, and P. H. Raven. 1973. Cultural Significance and Lexical Retention in Tzeltal-Tzotzil Ethnobotany. In Meaning in Mayan Languages, edited by M. S. Edmonson, pp. 143-164. Mouton, The Hague, NL.

Berlin, B., D. E. Breedlove and P. H. Raven. 1973. General Principles of Classification and Nomenclature in Folk Biology. American Anthropologist 75:214-242.

Boster, J., B. Berlin, and J. O'Neill. 1986. The Correspondence of Jivaroan to Scientific Ornithology. American Anthropologist 88:569-583. doi:10.1525/aa.1986.88.3.02a00020.

Bowern, C. 2007. On Eels, Dolphins, and Echidnas: Nyulnyulan Prehistory Through the Reconstruction of Flora and Fauna. In Verba Docenti: Studies in Historical and IndoEuropean Linguistics, Presented to Jay $H$. Jasanoff by Students, Colleagues, and Friends, edited by A. Nussbaum, pp. 39-53. Beechstave Press, Ann Arbor, MI.

Bowern, C. 2012. A Grammar of Bardi. Mouton De Gruyter, Berlin, DE.
Bowern, C., P. Epps, R. Gray, J. Hill, K. Hunley, P. McConvell, and J. Zentz. 2011. Does Lateral Transmission Obscure Inheritance in Hunter-Gatherer Languages? PLoS ONE 6:e25195. doi:10.1371/journal.pone.0025195.

Brown, C. H. 1984. Language and Living Things: Uniformities in Folk Classification and Naming. Rutgers University Press, New Brunswick, NJ.

Brown, C. H. 1999. Lexical Acculturation in Native American Languages. Oxford University Press, Oxford, UK.

Brown, C. H. 2000. Folk Classification: An Introduction. In Ethnobotany: A Reader, edited by P. Minnis. 65-68. University of Oklahoma Press, Norman, OK.

Brown, C. H. 2010. Development of Agriculture in Prehistoric Mesoamerica: The Linguistic Evidence. In Pre-Columbian Foodways, edited by J. Staller and M. Carrasco, pp. 71-107. Springer, New York, NY.

Brown, C. H, J. Kolar, B. J. Torrey, and P. Volkman. 1976. Some General Principles of Biological and Non-biological Folk Classification. American Ethnologist 3:73-85.

Brown, C. H, E. N. Anderson Jr., R. Bulmer, P. Drechsel, R. F. Ellen, T. E. Hays, T. N. Headland, L. Howe, D. C. Hyndman, K.-E. Jensen, B. Morris, and D. Reason. 1985. Mode of Subsistence and Folk Biological Taxonomy [and Comments and Reply]. Current Anthropology 26:43-64.

Brown, C. H., E. N. Anderson, B. Berlin, J. S. Boster, T. C. Schadeberg, and L. E. Visser. 1986. The Growth of Ethnobiological Nomenclature [and Comments and Reply]. Current Anthropology 27:1-19. doi:10.2307/2743019.

Burridge, K. 2012. Euphemism and Language Change: The Sixth and Seventh Ages. Lexis 7:65-92.

Chacon, T. in press. A Revised Proposal of Proto-Tukanoan Consonant Reconstruction and Tukanoan Family Classification. International Journal of American Linguistics.

Dahl, Ö. 2011. Tea. In The World Atlas of Language Structures Online, edited by M. S. Dryer and M. Haspelmath, wals.info/chapter/138.

Donohue, M., and T. Denham. 2009. Banana (Musa Spp.) Domestication in the AsiaPacific Region: Linguistic and Archaeobotanical Perspectives. Ethnobotany Research and Applications 7:293-332.

Ehret, C. 2011. History and the Testimony of Language. University of California Press, Berkeley, CA.

Emeneau, M. B. 1948. Taboos on Animal Names. Language 24:56-63. doi:10.2307/410287. 
Epps, P. 2009. Language Classification, Language Contact, and Amazonian Prehistory. Language and Linguistics Compass 3:581-606. doi:10.1111/j.1749-818X.2009.00126.x.

Epps, P. in press. Language and Subsistence Patterns in the Amazonian Vaupés. In The Languages of Hunter-gatherers: Global and Historical Perspectives, edited by T. Güldemann, P. McConvell and R. Rhodes, Cambridge University Press, Cambridge, UK.

Fleck, D. W., and R. S. Voss. 2006. On the Origin and Cultural Significance of Unusually Large Synonym Sets in Some Panoan Languages of Western Amazonia. Anthropological Linguistics 48:335-368.

Fowler, C. L. S., and N. Turner. 1999. Ecological/Cosmological Knowledge and Land Management among Hunter-gatherers. In Cambridge Encyclopedia of Hunters and Gatherers, edited by R. B. Lee and R. Daly, pp. 419-425. Cambridge University Press, Cambridge, UK.

Haspelmath, M., and U. Tadmor. 2009. Loanwords in the World's Languages: A Comparative Handbook. Mouton de Gruyter, Berlin, DE.

Hill, J. 2011. Borrowed Names and Indexical Function in the Northern Uto-Aztecan Botanical Lexicon. In Information and Its Role in Hunter-Gatherer Bands, edited by R. Whallon, W. A. Lovis and R. K. Hitchcock, pp. 167180. Cotsen Institute of Archaeology Press, Los Angeles, CA.

Hock, H. H., and B. D. Joseph. 1996. Language History, Language Change, and Language Relationship: An Introduction to Historical and Comparative Linguistics. Mouton de Gruyter, Berlin, DE.

Hunn, E. 1982. The Utilitarian Factor in Folk Biological Classification. American Anthropologist 84:830-847. doi:10.1525/aa.1982.84.4. 02a00070.

Johnston, T. H., and J. B. Cleland. 1933. The History of the Aboriginal Narcotic, Pituri. Oceania 4:201-223. doi:10.2307/40327460.

Lee, R. 1979. The !Kung San: Men, Women and Work in a Foraging Society. Cambridge University Press, London, UK.

Lightfoot, K. G., and O. Parrish. 2009. California Indians and Their Environment: An Introduction, Vol. 96. University of California Press, Berkeley, CA.

Maffi, L. 2005. Linguistic, Cultural, and Biological Diversity. Annual 29:599-617.

McConvell, P. 1997. Semantic Shifts between Fish and Meat and the Prehistory of PamaNyungan. In Boundary Rider: Essays in
Honour of Geoffrey O'Grady, edited by D. Tryon and M. Walsh, pp. 303-325. Pacific Linguistics, Research School of Pacific and Asian Studies, Australian National University, Canberra, ACT.

McConvell, P. 2009. Loanwords in Gurindji. In Loanwords in the World's Languages: A Comparative Handbook, M. Haspelmath and U. Tadmor, pp. 790-822. Mouton, The Hague, NL.

Medin, D., and S. Atran. 1999. Folkbiology. MIT Press, Cambridge, MA.

Nabhan, G. P., and S. St Antoine. 1993. The Loss of Floral and Faunal Story: The Extinction of Experience. In The Biophilia Hypothesis, edited by S. R. Kellert and E. O. Wilson, pp. 229-250. Island Press, Washington, DC.

Peterson, J. T. 1978. Hunter-Gatherer/Farmer Exchange. American Anthropologist 80:335351. doi:10.1525/aa.1978.80.2.02a00050.

Pinheiro, J., D. Bates, S. DebRoy, and D. Sarkar. 2012. Nlme: Linear and Nonlinear Mixed Effects Models. R package version 3.1-105.

Politis, G. 2007. Nukak: Ethnoarchaeology of an Amazonian People. Illustrated edition, translated by B. Alberto. Left Coast Press, Walnut Creek, CA.

Pozzobon, J. 1991. Parenté et demographie chez les Indiens Makú. PhD dissertation, Université de Paris VII.

Rice, K. 2004. Language Contact, Phonemic Inventories, and the Athapaskan Language Family. Linguistic Typology 8:321-343.

Rival, L. 2002. Trekking Through History. Columbia University Press, New York, NY.

Roberts, S., and J. Winters. 2012. Social Structure and Language Structure: The New Nomothetic Approach. Psychology of Language and Communication 16:89-112.

Seifart, F. 2011. Bora Loans in Resígaro: Massive Morphological and Little Lexical Borrowing in a Moribund Arawakan Language. Cadernos de Etnolingüística, Série Monografías 2. http://www.etnolinguistica.org/mono:2.

Sherratt, A. 1995. Introduction: Peculiar Substances. In Consuming Habits: Drugs in History and Anthropology, edited by J. Goodman, A. Sherratt and P. Lovejoy, pp. 1-46. Routledge, London, UK.

Simons, G. F. 1982. Word Taboo and Comparative Austronesian Linguistics. In Papers from the Third International Conference on Austronesian Linguistics, vol 3: Accent on Variety, edited by A. Halim, L. Carrington, and S. Wurm, pp 157-226, Pacific Linguistics, Canberra, ACT. 
Tadmor, U., M. Haspelmath, and B. Taylor. 2010. Borrowability and the Notion of Basic Vocabulary. Diachronica 27:226-246. doi:10.1075/ dia.27.2.04tad.

Timbrook, J. 2007. Chumash Ethnobotany: Plant Knowledge among the Chumash People of Southern California, Vol. 5. Santa Barbara Museum of Natural History Monographs, Santa Barbara, CA.

Turner, N. J. 1974. Plant Taxonomic Systems and Ethnobotany of Three Contemporary Indian Groups of the Pacific Northwest (Haida, Bella Coola, and Lillooet). Syesis 7:1-104.
Turner, N. J. 1988. "The Importance of a Rose": Evaluating the Cultural Significance of Plants in Thompson and Lillooet Interior Salish. American Anthropologist 90:272-290. doi:10.1525/aa.1988.90.2.02a00020.

Urban, M. 2010. Terms for the Unique Beginner: Cross-linguistic and Cross-Cultural Perspectives. Journal of Ethnobiology 30:203-230.

Watkins, C. 2000. The American Heritage Dictionary of Indo-European Roots. Houghton Mifflin Harcourt, Boston, MA.

Witkowski, S. R., C. H. Brown, and P. K. Chase. 1981. Where Do Tree Terms Come From? Man 16:1-14. doi:10.2307/2801972. 